\title{
The Effect of Separation Distance Between Informal Dwellings on Fire Spread Rates Based on Experimental Data and Analytical Equations
}

\author{
Antonio Cicione (D), Richard Walls, Zara Sander, Natalia Flores and Vignesh \\ Narayanan, Department of Civil Engineering, Stellenbosch University, \\ Stellenbosch, South Africa \\ Sam Stevens and David Rush*, School of Engineering, University of Edinburgh, \\ Edinburgh EH9 3JL, UK
}

Received: 13 March 2020/Accepted: 4 July 2020

\begin{abstract}
Globally, the number of informal settlement dwellings are increasing rapidly; these areas are often associated with numerous large fires. Unfortunately, until recently, very little research has been focused on informal settlement fire issues leaving any attempts to improve their fire safety lacking the evidence base to support effective-decision making. However, over the past 4 years, a limited number of researchers have looked at better understanding these fires through full-scale experimentation and numerical modelling; starting to provide the necessary evidence base and future research directions. It is with this background in mind that this paper seeks to provide a more fundamental understanding of the effect of dwelling separation distance on informal settlement fire spread based on full-scale experiments and analytical equations. In this paper two full-scale experiments were conducted. Both experiments consisted of multiple dwellings, with the main difference between the experiments being the separation distance. Fire spread times, heat release rates, door and window flow velocities, ceiling temperatures and incident heat fluxes were recorded and are reported for both experiments. Theoretical neutral planes are derived and compared to the experimental neutral planes, which show relatively good correlation. The paper continues by calculating the expected incident radiation and time-toignition, using the flux-time product method, of the two fire scenarios (i.e., the two experiments) through means of analytical equations, and these findings are compared to the experimental results. Through configuration factors, the paper shows the effect of separation distance, dwelling height and dwelling length on the times-to-ignition, where it is clear that the heat flux received by an adjacent dwelling decrease approximately exponentially as the distance between dwellings increases, and consequently, the time-to-ignition increases exponentially as the separation distance between dwellings increases.
\end{abstract}

* Correspondence should be addressed to: Antonio Cicione, E-mail: acicione@sun.ac.za; David Rush, E-mail: d.rush@ed.ac.uk 
Keywords: Informal settlements, Fire spread, Enclosure fire dynamics, Time-to-ignition, Thermal material properties

\section{Introduction}

Informal settlements, which are typically known by more derogatory names such as shantytowns, slums or ghettos, are often razed by large fires [1]. Informal settlements are extremely vulnerable to fire spread because they are inherently characterized by poor infrastructure, lack of basic services, poorly constructed structures and are often overcrowded [2]. Informal Settlement Dwellings (ISDs) are makeshift structures that are typically constructed from locally available materials in the immediate surroundings of the settlement [3]. Figure 1a-c depict typical ISDs and the intensity of an informal settlement fire.

Although numerous fire spread interventions had been proposed over the past decade [4], informal settlement fires still expose the one billion people that reside in these settlements to high risk of extreme losses (i.e., economical losses and death) [5]. Whilst fire related fatalities have decreased in the Global North, they have increased in the Global South [6]. It is expected that the population that reside in informal settlements will increase to 1.2 billion in Africa alone by 2050 [2], which will result in rapid unplanned settlement development. This will lead to more overpopulated informal settlements with even less formal infrastructure.

Recent studies have look at the understanding the fire dynamics within ISDs and understanding the fire spread between ISDs [3, 7-9] with the hope that the findings can assist local authorities when implementing fire spread interventions and also better their understanding of informal settlement fires. Cicione et al. [6] investigated the effect of cladding materials (steel cladding versus timber cladding) on fire spread based on two full-scale single ISD experiments. Cicione et al. [6] continued their study by developing Fire Dynamics Simulator (FDS) simulations, based on these full-scale experiments conducted, and from the simulation results determined a separation distance needed for fire spread not to occur. It was found that $3 \mathrm{~m}$ would be sufficient for fire spread not to occur in still wind conditions and based on a critical heat flux $(\mathrm{CHF})$ of $8.5 \mathrm{~kW} / \mathrm{m}^{2}$ for cardboard (i.e., the material sometimes used for internal lining in informal settlements, or for sealing openings).

Beshir et al. [10] also made use of FDS simulations to investigate the effect of ventilation conditions on fire spread. The paper considered a variety of horizontal roof opening positions and sizes, and studied their effect on the change in heat fluxes emitted from a door. It was found that roof openings reduce the heat fluxes emitted to the surroundings. Beshir et al. [11] investigated the effect of the position of a window opening with respect to a door opening on heat fluxes emitted to an adjacent structure. It was found that changing the position of a window opening with respect to a door opening could have a substantial effect on heat fluxes emitted. Cicione et al. [3] conducted 2 full-scale ISD experiments consisting of 3 dwellings each. The study specifically investigated the effect of timber cladding versus steel cladding on fire spread rates. The study found that timber clad dwellings are more prone to fire spread. 


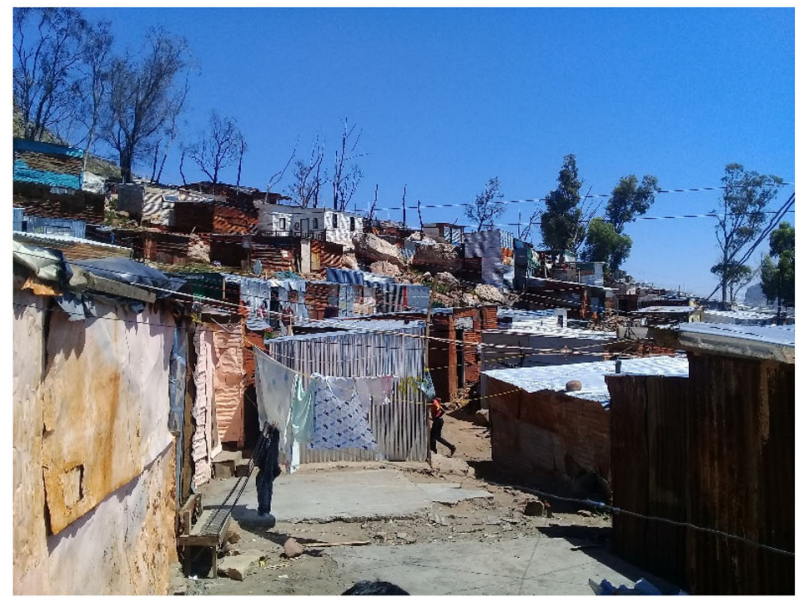

(a) Example of an informal settlement

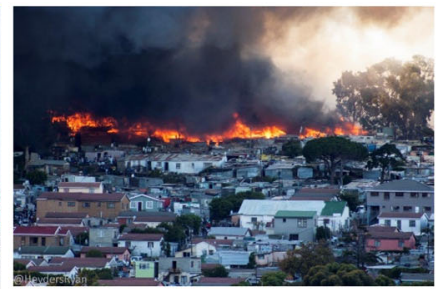

(b) Example of an informal settlement fire (Image used with permission of Ryan Heydenrych of Vulcan Wildfire Management)

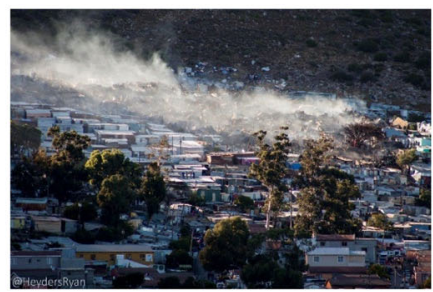

(c) Example of an informal settlement fire

\section{Figure 1. a Example of an informal settlement, b Example of an informal settlement fire (Image used with permission of Ryan Heydenrych of Vulcan Wildfire Management), c Example of an informal settlement fire.}

Gibson et al. [12] proposed a method to map historic informal settlement fires based on satellite imagery. The main concept of the proposed methodology is that there is a distinct change in roof reflectiveness pre and post-fire and by tracking this change in reflectiveness across a series of images, an informal settlement fire could be identified. One of the goals is to develop spatial metrics of different variables such as settlement density, edge density, slope, etc. to determine which variable/variables effect fire spread the most.

A number of researchers have investigated urban and wildland urban interface fire spread [13-15] which is mostly focused on formal housing (i.e., structures with thermally thick boundaries, less permeable structures compared to ISDs, less leakages compared to ISDs, etc.). This work provides background on such typical fire spread methods, which could potentially be incorporated when considering largescale fire spread in the future.

Although the researchers discussed above investigated fire spread behavior of informal settlements, our understanding of the different fire spread mechanisms is still in its infancy. Questions such as (a) how does separation distance effect fire spread? (b) how do leakages (i.e., the openings created by the flutes of corrugated steel sheets that is typically used as a cladding material, openings created as a result of poor construction methods, etc.) effect fire spread? (c) how do ventilation conditions effect fire spread? and (d) how do lining materials effect fire spread? are still unanswered. It is with this backdrop that this paper seeks to answer two very 
specific question: (1) How does the separation distance between ISDs effect the rate of fire spread based on full-scale experiments and analytical equations? and (2) how do the dwelling dimensions effect the rate of fire spread based on fullscale experiments and analytical equations? In this work, a method has been developed to calculate time-to-ignition between ISDs that is based on analytical equations. These equations are used to investigate the effect of (1) and (2). These equations are robust, but simple, and are derived from first principles, such that they could ultimately be used as a basis for semi-probabilistic modelling for fire spread of informal settlements.

\section{Experimental Set-Up}

At the end of 2019 a series of 9 full-scale mock ISD fire experiments, consisting of two dwellings each, were conducted at the Breede Valley Fire Department in Worcester, South Africa. The purpose of all experiments was to better understand fire spread between ISDs, by investigating the effect of variables such as lining materials, ventilation conditions and spacing between dwellings. In this work, 2 of the 9 experiments are considered and only the effect of the distance between dwellings is investigated in depth. The two experiments considered in this paper are identical, with the only controllable difference (that affects fire spread rates) was the spacing between the two dwellings, i.e., $1 \mathrm{~m}$ between dwellings for the first experiment (denoted as Exp 1) and $1.75 \mathrm{~m}$ between dwellings for the second experiment (denoted as Exp 2). The wind speed and direction for Exp 1 and Exp 2 are depicted in Fig. 2a and b, respectively. The wind data was capture approximately $10 \mathrm{~m}$ away from the experiments, towards the bottom left corner of Fig. 4, at a height of $2 \mathrm{~m}$ using a hemispherical cup-type anemometer. Zero degrees on the right y-axis indicates an east wind, as depicted in Fig. 4.

\subsection{Design of Dwellings}

All dwellings had a floor area identical to that of the ISO 9705 room $(3.6 \mathrm{~m} \times 2.4 \mathrm{~m})$, similar to ISDs tested by previous researchers [16], and had a height of $2.3 \mathrm{~m}$, similar to [3,6, 17]. The dwelling of fire origin (denoted as ISD1) was designed to be as simple as possible, in order to reproduce a consistent fire across all experiments. Note that ISD1 was kept the same for all experiments. Hence, ISD1 only had a single door opening with internal dimensions of $2.05 \mathrm{~m}$ (height) $\times 0.85 \mathrm{~m}$ (width), as depicted in Fig. 3. ISD1 was clad with galvanized IBR (Inverted Box Rib) sheeting $(0.8 \mathrm{~mm}$ thick) and had a steel frame. The sheeting was fixed to the steel frame with self-drilling hex head screws. The flute height of the IBR sheeting is $36 \mathrm{~mm}$ and all leakages (i.e., openings created by the corrugation of the steel sheets) were closed with ceramic blanket and checked prior to each experiment. The steel frame consisted of $38 \mathrm{~mm} \times 38 \mathrm{~mm} \times 2 \mathrm{~mm}$ square hollow sections that were welded together on site.

The target dwellings (denoted as ISD2) were clad with galvanized corrugated steel sheeting $(0.5 \mathrm{~mm}$ thick) and were fixed to a timber frame (where the crosssectional area of the timber pieces used were $50 \mathrm{~mm} \times 50 \mathrm{~mm}$ ) using self-drilling 


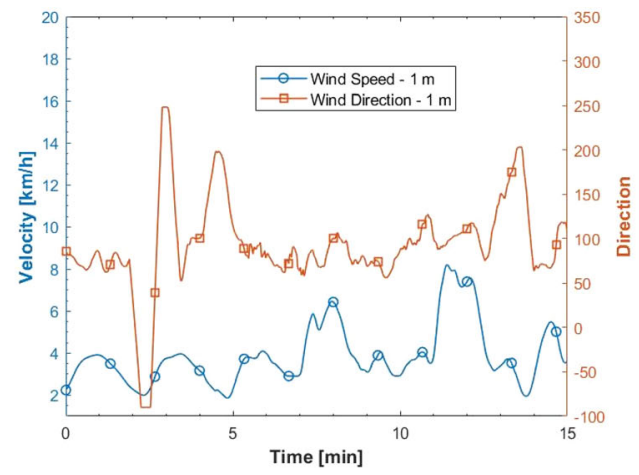

(a) Wind Speed and Direction for Exp 1

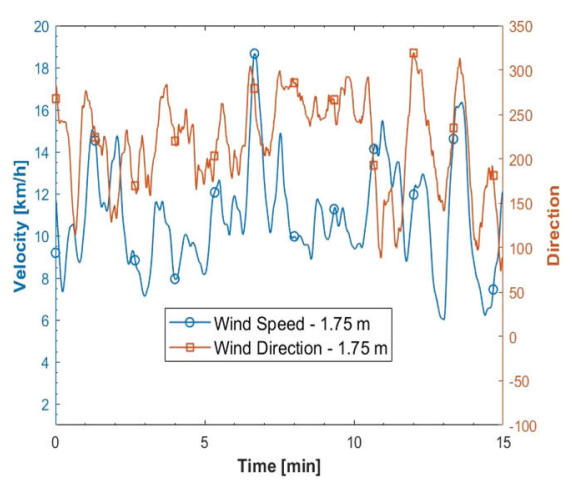

(b) Wind Speed and Direction for Exp 2

\section{Figure 2. a Wind speed and direction for Exp 1, b wind speed and direction for Exp 2.}

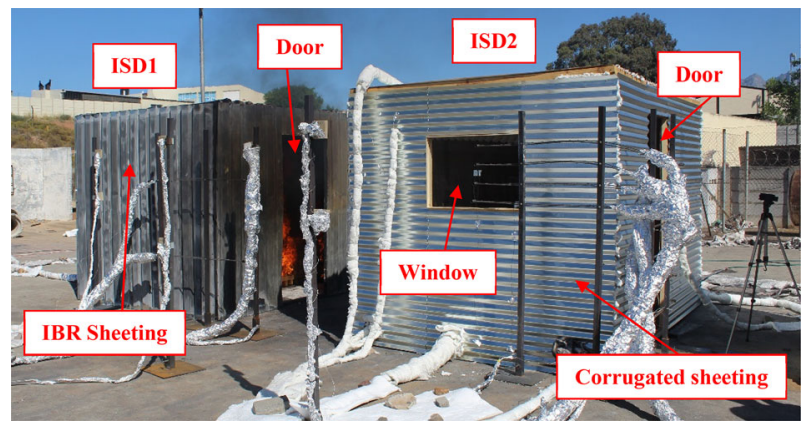

\section{Figure 3. Visual depiction of experimental set-up.}

hex head screws. The timber lengths were fixed together using self-tapping hex head screws. The flute height of the corrugated sheeting is $18 \mathrm{~mm}$ and all openings were closed with ceramic blanket. In both experiments, ISD2 had two openings, which included a door in the long wall with internal dimensions of $2.05 \mathrm{~m}$ (height) $\times 0.85 \mathrm{~m}$ (width) and a window in the short wall with internal dimensions of $0.6 \mathrm{~m}$ (height) $\times 0.85 \mathrm{~m}$ (width), placed $1.25 \mathrm{~m}$ from the ground, as depicted in Fig. 3. As depicted in Fig. 4, the separation distance between ISD1 and ISD2 for Experiment $1(\operatorname{Exp} 1)$ and Experiment $2(\operatorname{Exp} 2)$ were $1 \mathrm{~m}$ and $1.75 \mathrm{~m}$, respectively. In addition to the change in separation distance, the window opening in the short wall was closed with a $3 \mathrm{~mm}$ single glazed glass, for Exp 2 (which does not affect the initial fire spread between dwelling that is being investigated in this paper). In both experiments, an isolated standing wall (ISD right wall denoted as RW) was erected at a distance from ISD2, as depicted in Fig. 4. The RW was also constructed from corrugated steel sheets, fixed to a steel frame. For Exp 1 and Exp 2 the distance between ISD2 and RW were $2 \mathrm{~m}$ and $1.5 \mathrm{~m}$, respectively. 


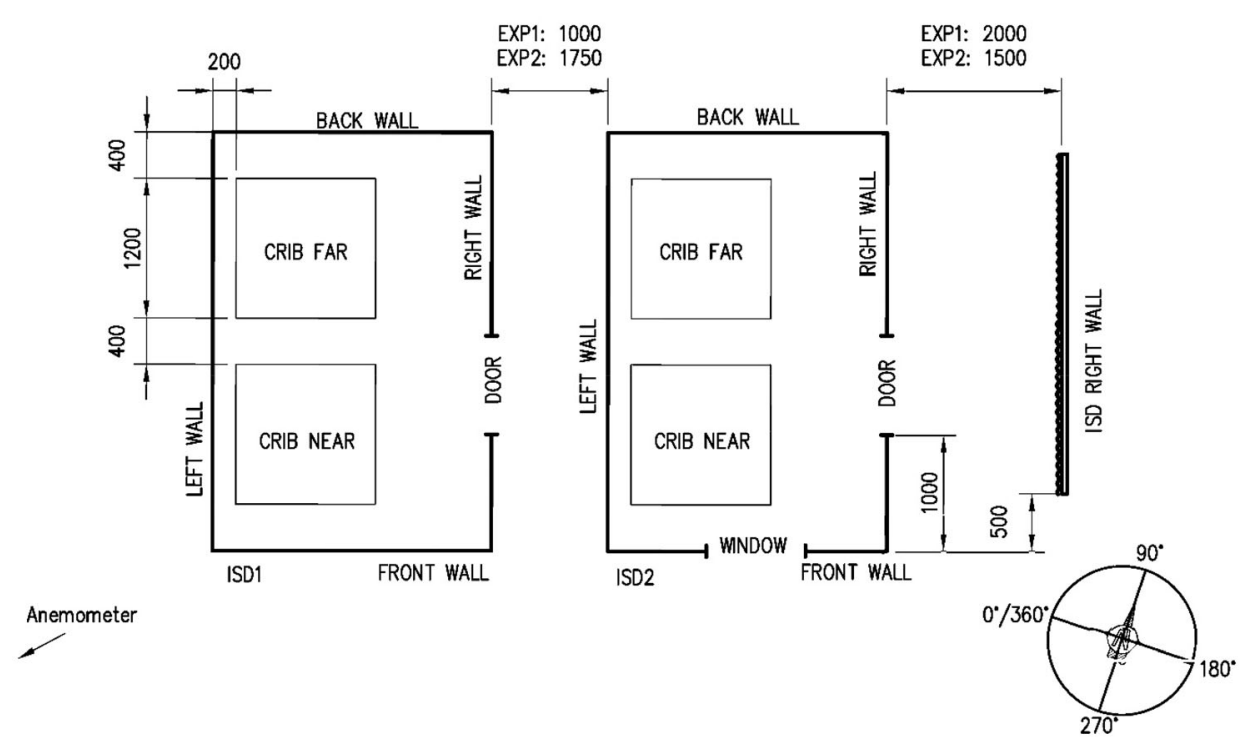

Figure 4. Experimental sełup (all dimensions in $\mathbf{m m}$ ).

\subsection{Fuel}

The fuel load in real ISDs varies substantially and can be anything from $410 \mathrm{MJ} /$ $\mathrm{m}^{2}$ to $2000 \mathrm{MJ} / \mathrm{m}^{2}$ [18]. Even though the fuel load range significantly, it is clear from previous work that these dwellings are ventilation controlled $[3,6-8,16]$ and that these dwellings collapse before the fuel burns out [17], implying that fuel load alone would not have a substantial effect on the fire dynamics and heat fluxes produced once the fully developed stage is reached.

In this work, two pine timber cribs (each was approximately $130 \mathrm{~kg}$ ) were placed $0.2 \mathrm{~m}$ from the long wall (see Fig. 4) with a separation distance of $0.4 \mathrm{~m}$ between the cribs and the short side walls, as depicted in Fig. 4. Each crib consisted of 10 layers of 10 sticks with a dimension of $0.04 \mathrm{~m} \times 0.06 \mathrm{~m} \times 1.2 \mathrm{~m}$ and an approximate density of $450 \mathrm{~kg} / \mathrm{m}^{3}$. The moisture content of the timber was $4 \%$.

For free burning conditions, these cribs would have had a maximum surfacecontrolled mass loss rate (MLR) of $0.39 \mathrm{~kg} / \mathrm{s}$ combined according to [19]. The heat of combustion (HoC) of timber used was $17 \mathrm{MJ} / \mathrm{kg}$ as measured by a bomb calorimeter, thus giving a maximum surface-controlled heat release rate (HRR) of 6.7 MW. It is well-known that the ventilation-controlled MLR is given by the ventilation factor multiplied by a factor of $0.12[19,20]$. Unlike pool fires than can burn in an enclosure in a highly fuel-rich manner, timber cribs have a burning limit of approximately $37 \%$ fuel rich [17]. The ventilation-controlled limit is thus presumed to account for the combined effects of heating and vitiating the crib intake air. In this case, the ventilation-controlled HRR of ISD1 and ISD2 are $5 \mathrm{MW}$ and 5.99 MW, respectively. Hence, in both cases the dwellings were expected to be ventilation-controlled. 
In addition to the timber cribs, ISD2 was lined with cardboard (for both experiments) to mimic reality [3]. In order to keep the fire as reproduceable as possible, ISD1 was not lined with cardboard. It was however regarded as important to line ISD2 with cardboard as the lining material is typically associated as the primary fuel of ignition $[3,6,16]$, and/or significantly affect the growth phase of the fire. Figure 5 visually depicts cardboard and cribs in ISD2.

ISD1 was ignited by igniting 8 small bags filled with a $400 \mathrm{~mm} \times 400 \mathrm{~mm}$ piece of kerosene-soaked hessian, with one bag placed in each of the bottom 4 corners of each crib.

\subsection{Measurements}

In both experiments a variety of measurements were captured. In both ISD1 and ISD2, the MLR data was captured using scales with an accuracy of $10 \mathrm{~g}$ (the MLR of each timber crib was measure individually in these experiments). The gas temperatures that were recorded during these experiments were measured using $\mathrm{K}$ Type thermocouples (1.5 $\mathrm{mm}$ tip diameter). Incident radiation was measured using Thin Skin Calorimeters (TSCs) that were calibrated against a water-cooled heat flux gauge, stationed at various distances from the door of ISD2 during the fullscale experiments. Gas flow velocities were captured at the door and window for ISD2 using bi-directional flow probes. The temperature data was captured at $0.2 \mathrm{~Hz}$ and the voltage data (flow probe and scale measurements) was captured at $1 \mathrm{~Hz}$. The equipment layout, the equipment key and the equipment detailing of the right wall are depicted in Fig. 6. The abbreviation in brackets next to each instrumentation icon indicates the type of instrumentation, where Thin Skin Calorimeter is abbreviated as TSC, Thermocouple is abbreviated as TC and bi-directional Flow Probe is abbreviated as FP. The number next to the instrumentation abbreviation (Thin Skin Calorimeter $\rightarrow$ TSC, Thermocouple $\rightarrow$ TC, and Flow Probe $\rightarrow$ FP) indicates the number of instruments in a particular equipment tree location. The instrumentation spacings of the equipment trees are depicted in Fig. 7. Note that the flow probes were orientated perpendicular to all openings (i.e. from left to right of Fig. 4 for the door and top to bottom of Fig. 4 for the window) and parallel (i.e. from the bottom to top in Fig. 4) to the allay.

\section{Experimental Results}

In the sections that follow, the experimental results of Experiment 1 (Exp 1) and Experiment $2(\operatorname{Exp} 2)$ are discussed in detail. The experimental results are then followed by a discussion comparing the two experiments and highlighting what has been learned from these experiments in terms of the effect of separation distance on fire spread rates.

\subsection{Experiment 1 (Exp 1): 1.0 m Spacing}

The sections above describe the experimental setup of Exp 1 (Fig. 4), the equipment configuration (Fig. 6), the wind conditions during the experiment (Fig. 2a) 


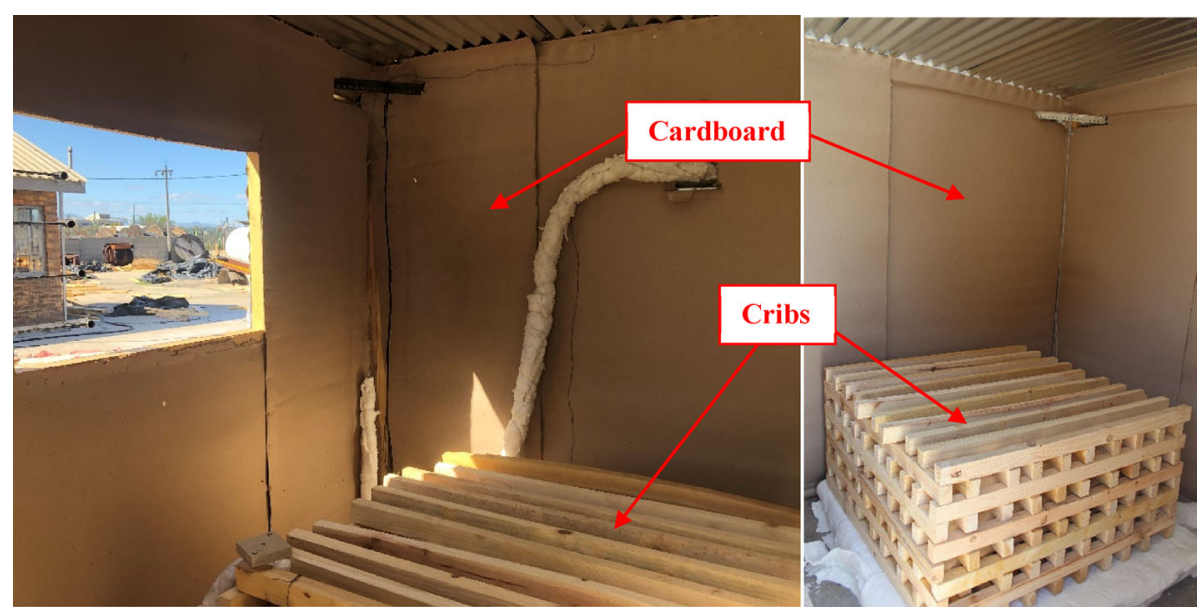

\section{Figure 5. Visual depiction of cardboard and timber cribs.}

and the fuel content of both dwellings (Fig. 5). ISD1 was ignited at the 8 corners of the two cribs. After ignition, a fully developed fire stage was reached in approximately $4.3 \mathrm{~min}$. For approximately $1 \mathrm{~min}$ before the fully developed fire stage was reached, flames were seen emerging out of the door causing flame impingement onto ISD2 within seconds after emerging (Fig. 8a). Approximately 30-60 s later (after the fully developed stage was reached), an exposed timber frame piece ignited externally on the left wall of ISD2 (Fig. 8a). This rapidly led (approximately $30 \mathrm{~s}$ ) to the cardboard lining of ISD2 igniting (Fig. 8b). It should be noted that the ceramic blanket used to seal the leakages is not completely impermeable, hence some smoke did accumulate at the ceiling level, in ISD2, prior to ignition (Fig. 8b). At this stage flames spread across the cardboard (Fig. 8c), which generated enough heat to ignite the cribs and flashover ensued approximately 2.4 min after the cardboard ignited. ISD2 reached a fully developed fire stage approximately $2.8 \mathrm{~min}$ after the cardboard lining ignited (Fig. 8d).

Figure 9 depicts the HRR for both ISD1 and ISD2 along with the calculated ventilation-controlled HRR, and Fig. 10 depicts the ceiling temperatures for ISD1. The label ISD1_Roof1 refers to the ceiling thermocouple closest to the front wall of ISD1, and ISD1_Roof2 refers to thermocouple furthest from the front wall of ISD1. Figure 6 depicts both the location of the scales and the location of the ceiling thermocouples.

The calculated ventilation-controlled MLR is based on the ventilation factor, $A_{0} \sqrt{H_{0}}$, where $A_{0}$ is the total area of the openings and $H_{0}$ is the area-weighted equivalent opening height), multiplied by a factor of 0.12 to account for the combined effects of heating and vitiating the crib intake air, as discussed in above. In this case, the calculated ventilation-controlled HRR $(\mathrm{HRR}=\mathrm{MLR} \times \mathrm{HoC})$ is lower than the maximum HRR measured (indirectly by the scales) during the experiments. This could be a result of some amount of leakage that was present during the experiment and that the ceramic blanket did not act as a perfectly 


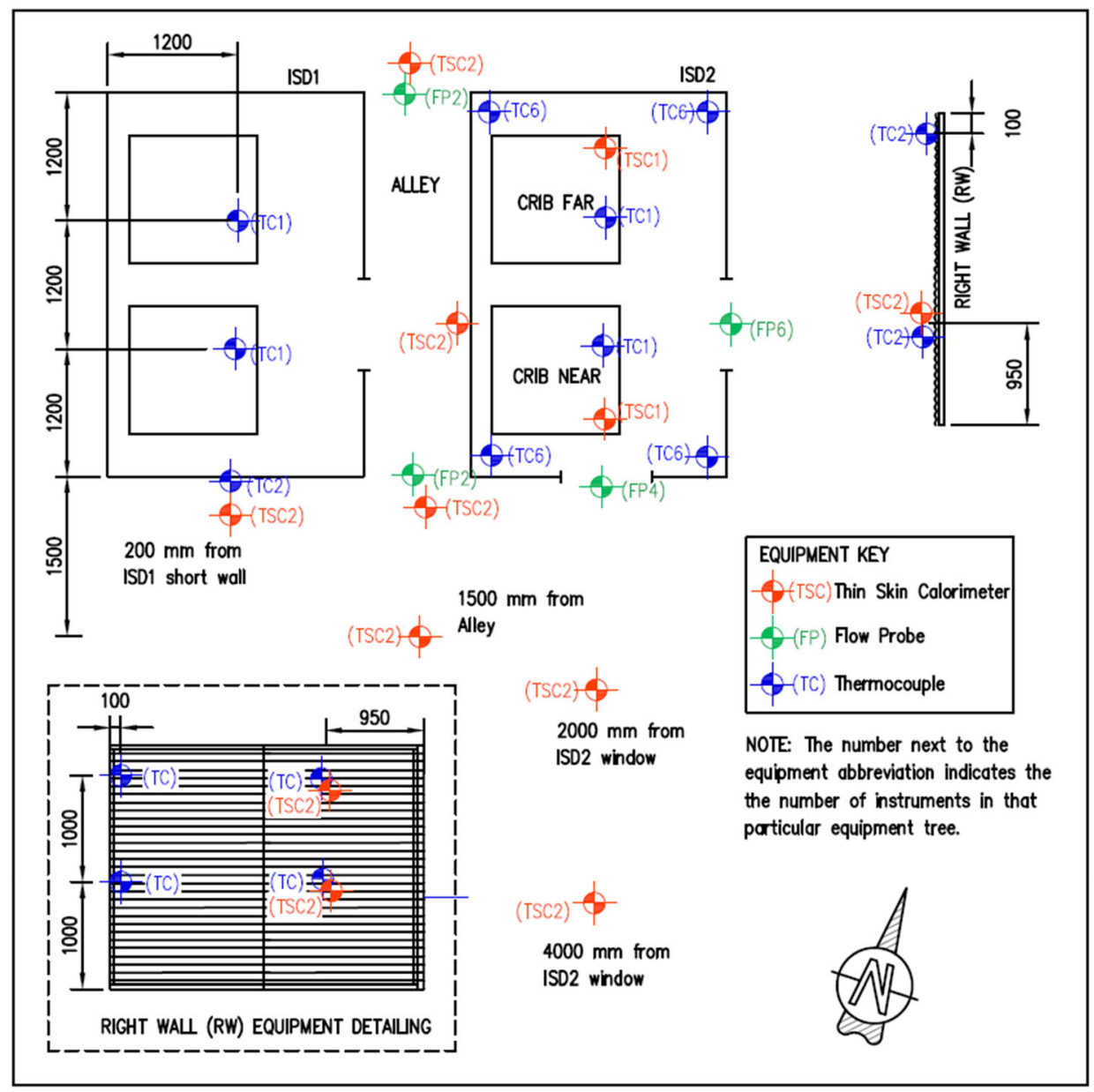

\section{Figure 6. Equipment layout (top), equipment key (middle right), and right wall detailing (bottom left).}

impermeable material. The maximum recorded HRR in ISD1 and ISD2 were 6.5 MW (assuming a $\mathrm{HoC}$ of $17 \mathrm{MJ} / \mathrm{kg}$, a ventilation factor of 3.2 is required to reach a $\mathrm{HRR}$ of $6.5 \mathrm{MW}$ ) and $8.4 \mathrm{MW}$ (assuming a $\mathrm{HoC}$ of $17 \mathrm{MJ} / \mathrm{kg}$, a ventilation factor of 4.1 is required to reach a HRR of $8.4 \mathrm{MW}$ ), respectively. The average ceiling temperature of ISD1 during the fully developed stage (between $4 \mathrm{~min}$ and $16 \mathrm{~min}$ ) was $901{ }^{\circ} \mathrm{C}$ and the maximum recorded ceiling temperature was $963^{\circ} \mathrm{C}$. Real ISDs are often highly permeable (possibly far in excess of that observed here), due to imperfect materials and construction means available, meaning that ventilation in reality is very difficult to define. Furthermore, leakages may be stopped up with combustible draught-stoppers (e.g., newspaper pressed into holes), which burn through rapidly, leading to quick increases in ventilation. 


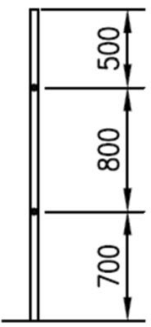

ALLEY FP TREE

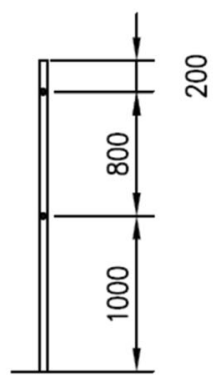

$\frac{\text { ALLEY TSC TREE }}{1: 50}$

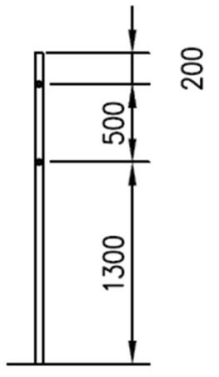

OTHER TSC TREE $1: 50$
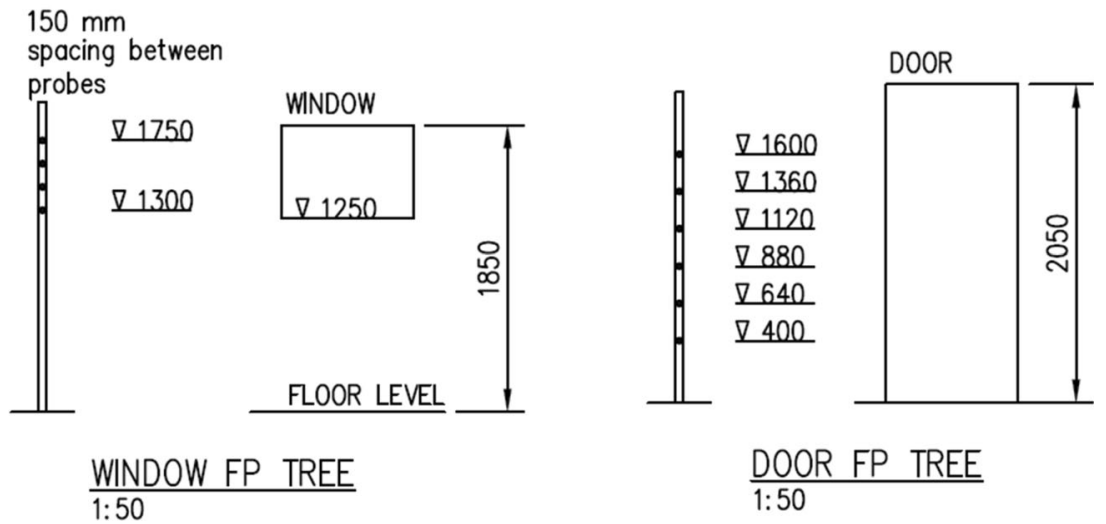

\section{Figure 7. Instrumentation heights for the various equipment trees.}

Figure 11a-d depict the back left, back right, front left and front right thermocouple tree readings, respectively. The annotation that this paper uses for front wall and back wall is shown in Fig. 4. The positions of the thermocouple trees are depicted in Fig. 6. Each tree had 6 thermocouples labelled from 1 (top TC) to 6 (bottom TC), with the following spacing: $2200 \mathrm{~mm}, 2150 \mathrm{~mm}, 2050 \mathrm{~mm}$, $1900 \mathrm{~mm}, 1700 \mathrm{~mm}$ and $1550 \mathrm{~mm}$ from floor level. The TC trees were constructed by fixing the TCs to a steel cable and suspending the cables from the roof perimeter beams of ISD2, by fixing the cables to the timber with screws. After thorough investigation of the data and video footages, it is clear that the sudden dips in temperatures across the height of the TC trees are as a result of the steel cables falling to ground level. Unfortunately, the charring of the timber resulted in the screws pulling out. Hence, temperatures after the trees falling are not depicted in Fig. 11a-d. Ignition shown on all graphs below references to the ignition of the cardboard lining and not ignition of the exposed timber frame.

The flow fields at the window and door were also captured with bi-directional flow probes and are depicted in Fig. 12a and b, respectively. 


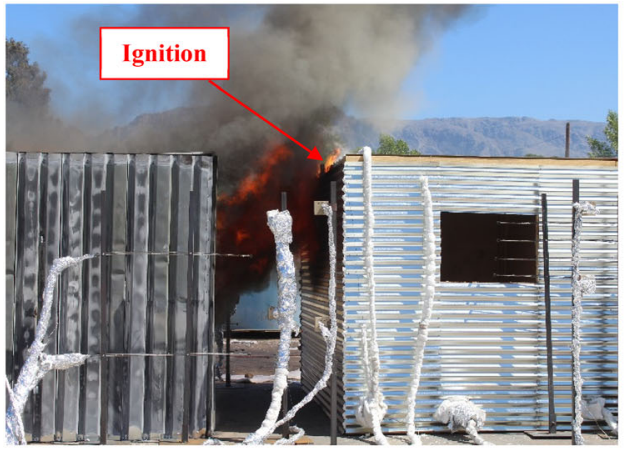

(a) Flames emerging from ISD2 and igniting an exposed timber piece of ISD2

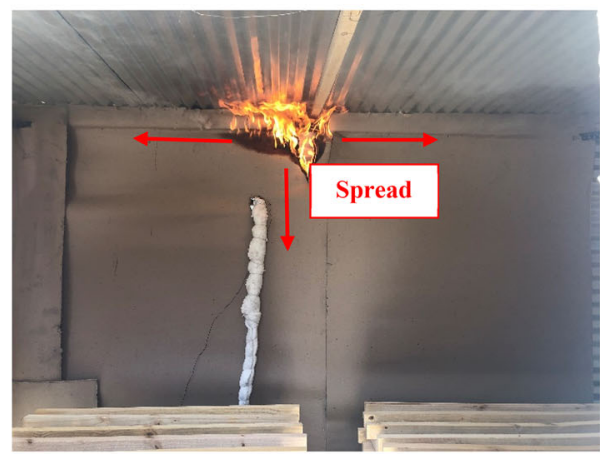

(c) Spread across the cardboard lining of ISD2

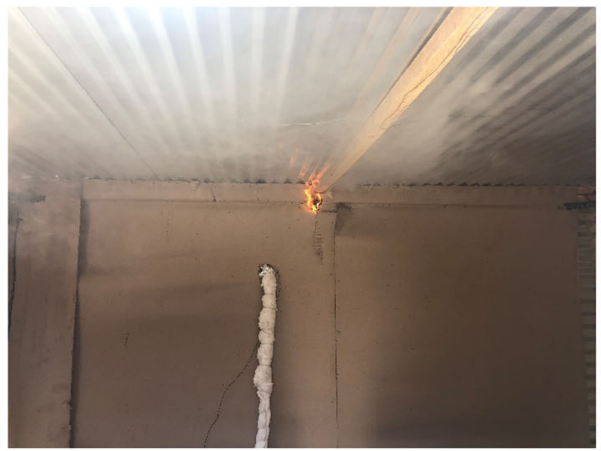

(b) Cardboard lining ignition of ISD2

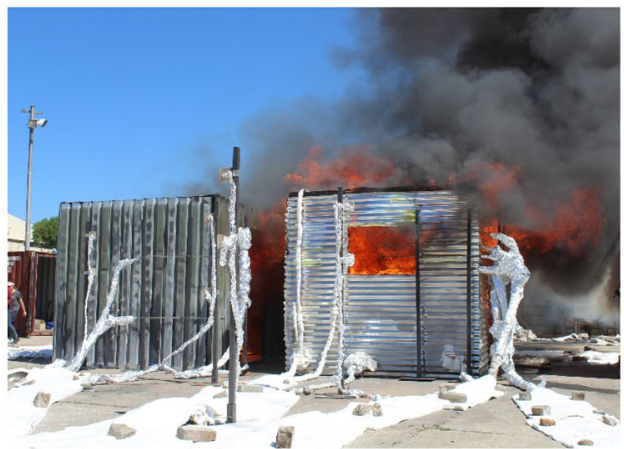

(d) Fully developed fire in ISD2

Figure 8. a Flames emerging from ISD2 and igniting an exposed timber piece of ISD2, b Cardboard lining ignition of ISD2, c Spread across the cardboard lining of ISD2, d Fully developed fire in ISD2.

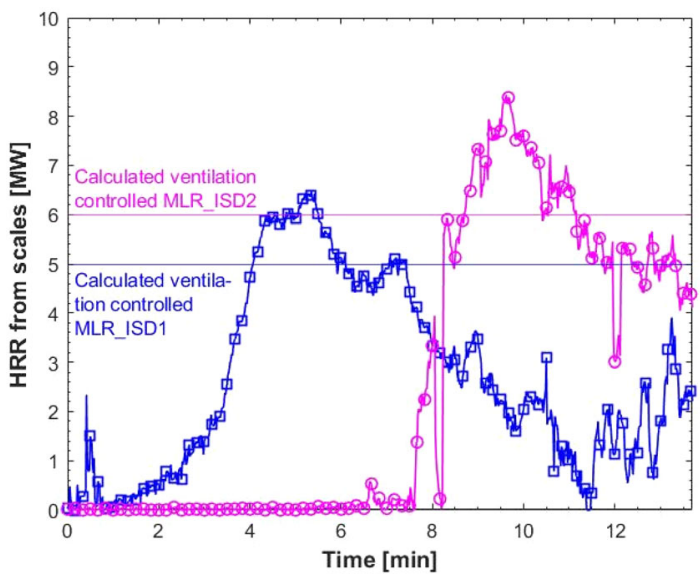

Figure 9. HRR of ISD 1 and ISD2, measured by the scales. 


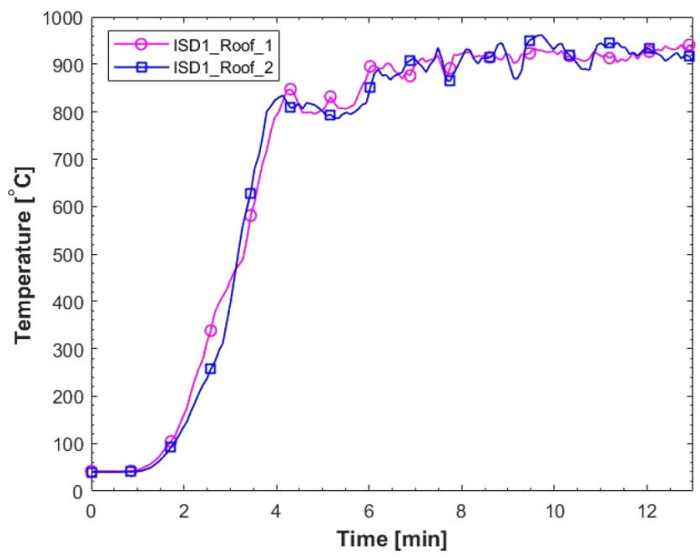

\section{Figure 10. Ceiling temperatures for ISD 1 .}

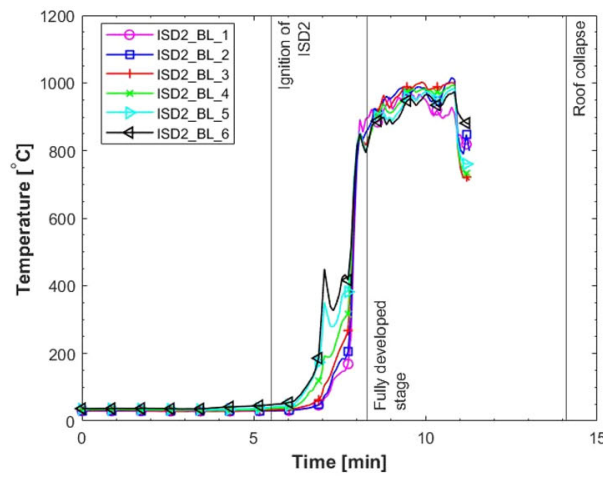

(a) Back left thermocouple tree

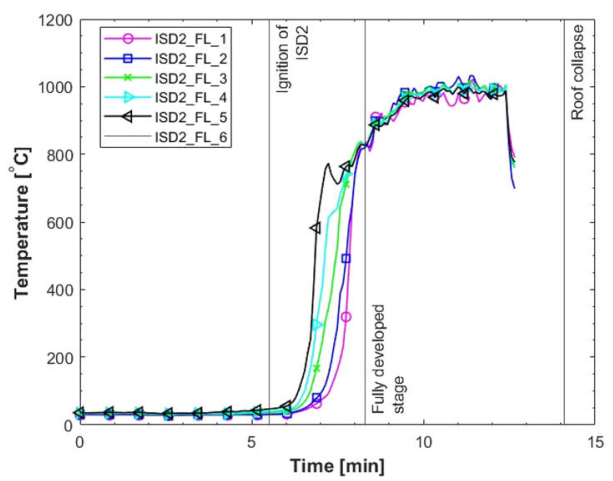

(c) Front left thermocouple tree

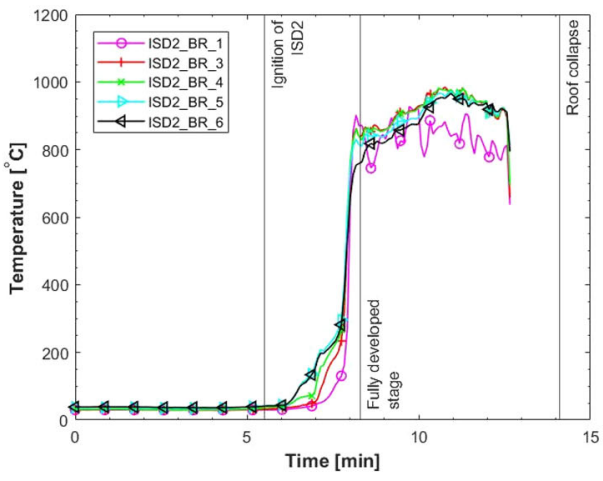

(b) Back right thermocouple tree

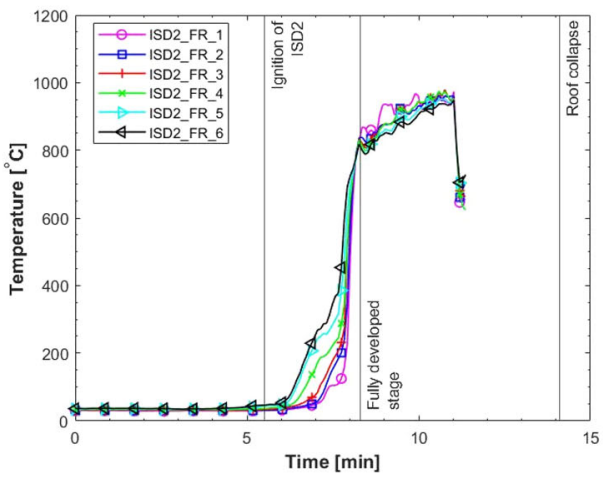

(d) Front right thermocouple tree

Figure 11. a Back left thermocouple tree, b Back right thermocouple tree, c Front left thermocouple tree, d Front right thermocouple tree. 


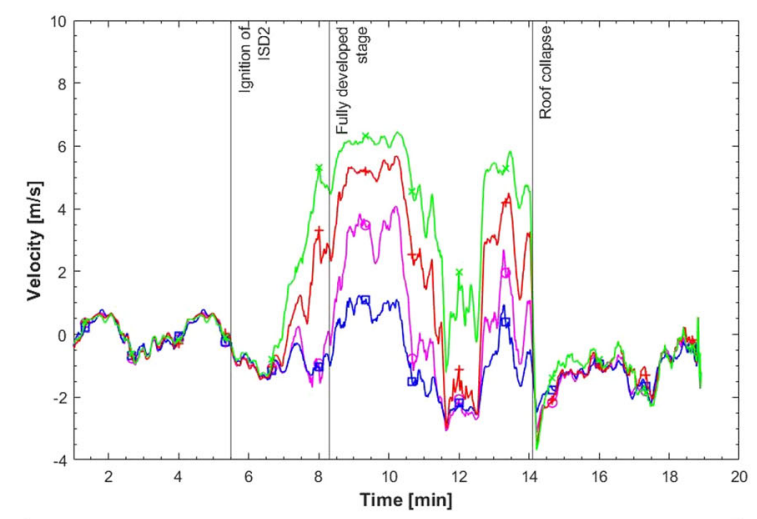

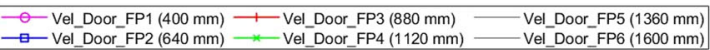

(a) Velocity readings at the window of ISD2

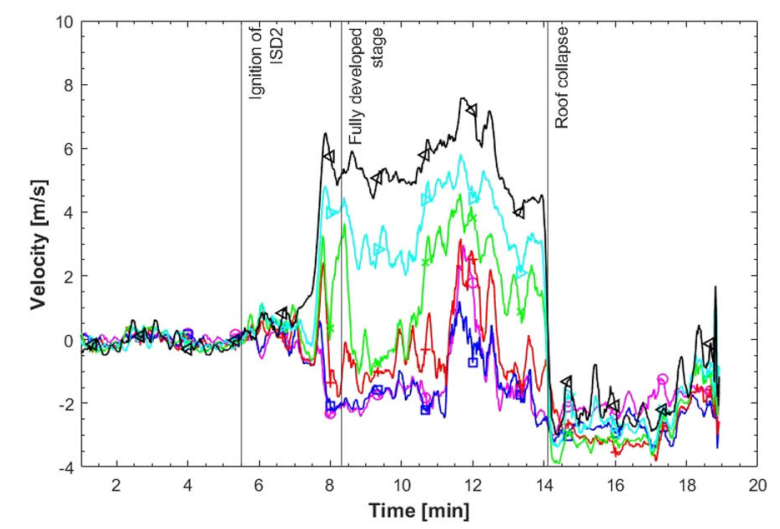

- -Vel_Door_FP1 $(400 \mathrm{~mm}) \longrightarrow$ - Vel_Door_FP3 $(880 \mathrm{~mm}) \longrightarrow$ Vel_Door_FP5 $(1360 \mathrm{~mm})$ ๑-Vel_Door_FP2 $(640 \mathrm{~mm})$ - *Vel_Door_FP4 $(1120 \mathrm{~mm})$-4 Vel_Door_FP6 $(1600 \mathrm{~mm})$

(b) Velocity readings at the door of ISD2

\section{Figure 12. a Velocity readings at the window of ISD2, b Velocity readings at the door of ISD2.}

Considering the door velocities between 8 and 11 min (i.e., from the start of the fully developed stage up to $11 \mathrm{~min}$ where an increase in wind speeds causes the neutral plane to shift, which is describe in detail in the section below) the neutral plane is around $1180 \mathrm{~mm}$ (i.e., just above FP4). The neutral plane can be calculated and compared to the measured value. In "Appendix 1", an analytical equation is derived to calculate the neutral plane for these ISDs. By substituting $W_{w}=0.85 \mathrm{~m}, \rho_{g}=353 / T_{g}$, where the measured gas temperature is approximately $1223 \mathrm{~K}, H_{W T}=1.85 \mathrm{~m}, H_{W B}=1.25 \mathrm{~m}, W_{D}=0.85 \mathrm{~m}, \rho_{a}=353 / T_{a}$, where the measured ambient temperature is approximately $297 \mathrm{~K}$, and $H_{D}=2 \mathrm{~m}$, into Equation (11) yields a neutral plane height of $H_{N}=0.94 \mathrm{~m}$. This is $320 \mathrm{~mm}$ lower than the measured neutral plane height of approximately $1180 \mathrm{~mm}$. It should be noted 
that the neutral plane height calculated above (also see "Appendix 1") did not account for the effect of wind. In this case, the wind direction (refer to Fig. 2a), which is in the $-x$ direction as depicted in Fig. 30, increases the outside pressure on the face that it is blowing against (as depicted in Fig. 30) resulting in an increased neutral plane height, and causes suction on the other faces resulting in an decrease in neutral plane height on those faces.

Thoroughly investigating Fig. $12 \mathrm{a}$ and $\mathrm{b}$ a strange phenomenon can be seen, where approximately between $11 \mathrm{~min}$ and $13 \mathrm{~min}$, there is a sudden increase in the outwards flow through the door and a sudden increase in inwards flow through the window. This phenomenon can also be explained in terms of the effect of wind on the pressure profile. By overlaying the wind speed with the window velocities (Fig. 13), one can clearly see that the spike in wind speed (blowing from south to north) increased the pressure at the window (as depicted in Fig. 30) which resulted in the ambient pressure rising at the window, thus retarding the flow of smoke and flames from the window opening and essentially holding the hot gases within the dwelling. However, a build-up of pressure is created within the dwelling, and this is sufficient to drive the flow of smoke and flames out of the door opening.

Figure 14a depicts the incident radiation measured at the left wall of ISD2 at roof height. Figure $14 \mathrm{~b}$ depicts the incident radiation measured at the RW at a height of $2 \mathrm{~m}, 2 \mathrm{~m}$ away from the window at a height of $1.8 \mathrm{~m}$ and $4 \mathrm{~m}$ away from the window at a height of $1.8 \mathrm{~m}$. For the locations of the TSCs refer to Fig. 6.

The heat fluxes measured at 2 meters away from the door (Fig. 14b) is similar to the heat fluxes measured by previous researchers $[3,16]$. The average incident heat flux onto the left wall of ISD2 (Fig. 14a), during the fully developed stage of ISD1 until ignition of ISD2 was approximately $33 \mathrm{~kW} / \mathrm{m}^{2}$. It should be noted that the cable of the TSC placed on the left wall of ISD2, was exposed to flames once the cardboard of ISD2 ignited (at approximately $5.5 \mathrm{~min}$ ), thus the results after the ignition of ISD2 should be interpreted accordingly. The RW ( $2 \mathrm{~m}$ from ground level), $2 \mathrm{~m}$ from the window of ISD2 (1.8 $\mathrm{m}$ from ground level) and 4 meters from the window of ISD2 $(1.8 \mathrm{~m}$ from ground level) reached a maximum heat flux of $62 \mathrm{~kW} / \mathrm{m}^{2}, 28 \mathrm{~kW} / \mathrm{m}^{2}$ and $17 \mathrm{~kW} / \mathrm{m}^{2}$, respectively.

The peak in heat flux onto the RW at approximately $8 \mathrm{~min}$ is as a result of the cardboard lining burning similar to what was observe in previous experimental work [3, 6]. At approximately 13-15 min, the roof sheets start to open (as seen from video footage taken from above) allowing the hot gases to escape and the flame sizes from the openings to reduce, and this is evident in the heat flux curve recorded by the RW TSC.

\subsection{Experiment 2 (Exp 2): 1.75 m Spacing}

The sections above described the experimental setup of Exp 2 (Fig. 4), the equipment configuration (Fig. 6), the wind conditions during the experiment (Fig. 2b) and the fuel content of both dwellings (Fig. 5). ISD1 was ignited at the all 8 corners of the two cribs. After ignition a fully developed fire stage was reached in 


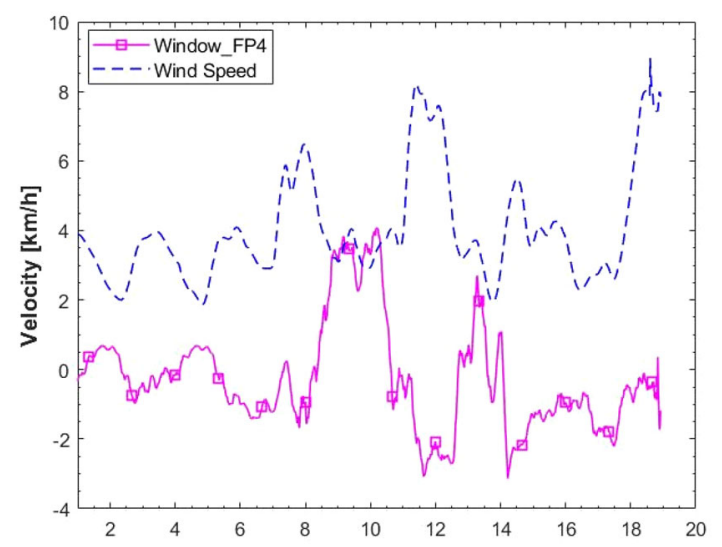

Figure 13. Door velocity measured by FP and wind speed.

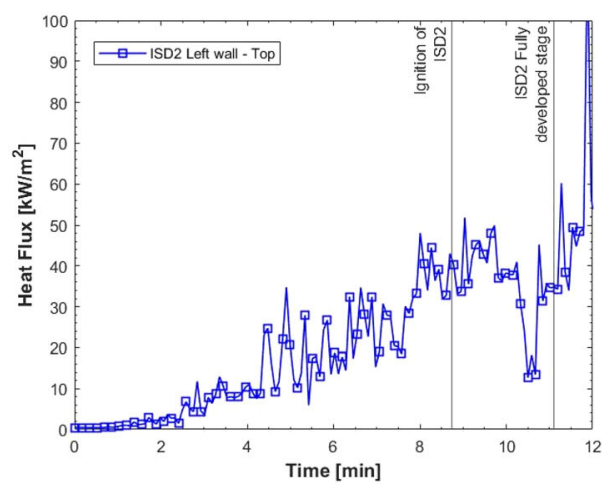

(a) Incident heat flux at the left walls of ISD2 at flute height

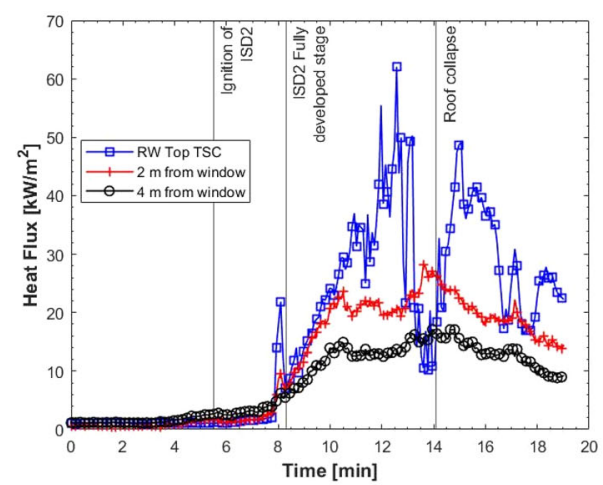

(b) Incident heat fluxes in front of openings of ISD2

\section{Figure 14. a Incident heat flux at the left walls of ISD2 at flute height, b Incident heat fluxes in front of openings of ISD2.}

approximately $3.5 \mathrm{~min}$. At this stage, flames were seen emerging out of the door causing some pulsed flame impingement onto ISD2. Within approximately $7 \mathrm{~min}$ (after ignition of ISD1), an exposed timber frame piece ignited on the left wall of ISD2 (Fig. 15a), which led to the cardboard lining of ISD2 igniting (Fig. 15b) at approximately $8.75 \mathrm{~min}$. The flames spread across the cardboard (Fig. 15c) generating enough heat to ignite the cribs and flashover ensued within approximately $2 \mathrm{~min}$ after the cardboard ignited. ISD2 reached a fully developed fire state approximately $2.4 \mathrm{~min}$ after the cardboard lining ignited (Fig. 15d).

Figure 16 depicts the HRR for both ISD1 and ISD2 along with the calculated ventilation controlled HRR, and Fig. 17 depicts the ceiling temperatures for ISD1. The label ISD1_Roof1 refers to the ceiling thermocouple closest to the front wall of ISD1, and ISD1_Roof2 refers to thermocouple furthest from the front wall of 


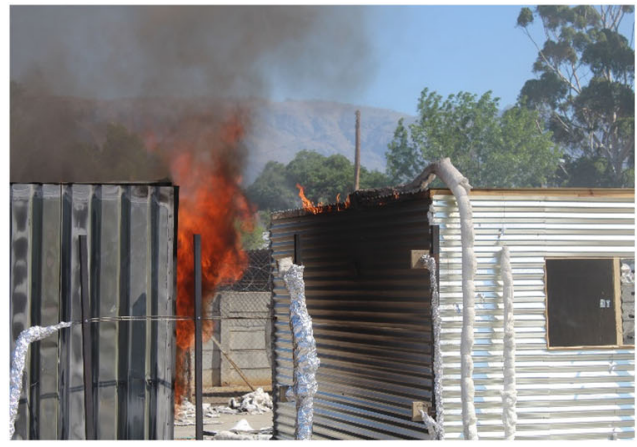

(a) Flames emerging from ISD2 and igniting an exposed timber piece of ISD2

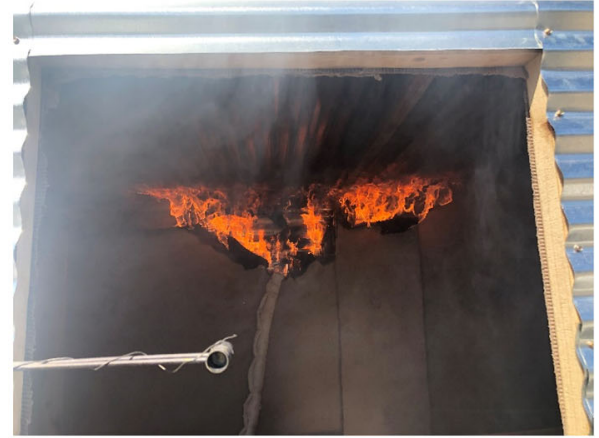

(c) Spread across the cardboard lining of ISD2

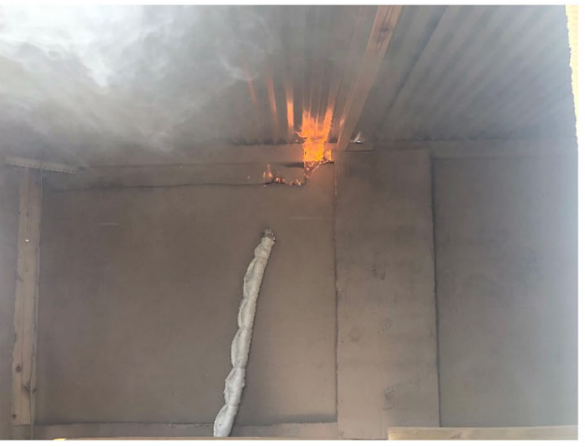

(b) Cardboard lining ignition of ISD2

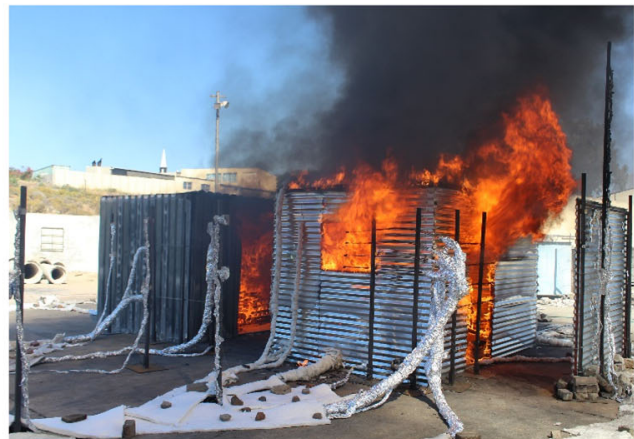

(d) Fully developed fire in ISD2

Figure 15. a Flames emerging from ISD2 and igniting an exposed timber piece of ISD2, b Cardboard lining ignition of ISD2, c Spread across the cardboard lining of ISD2, d Fully developed fire in ISD2.

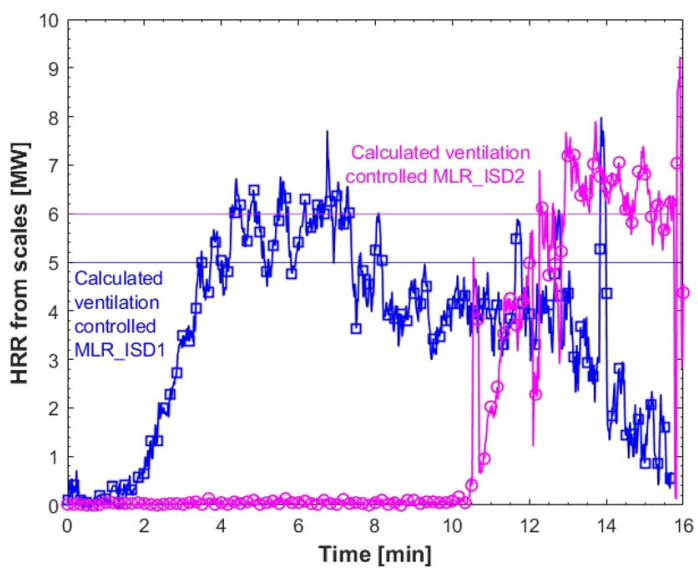

Figure 16. HRR of ISD 1 and ISD2, measured by the scales. 


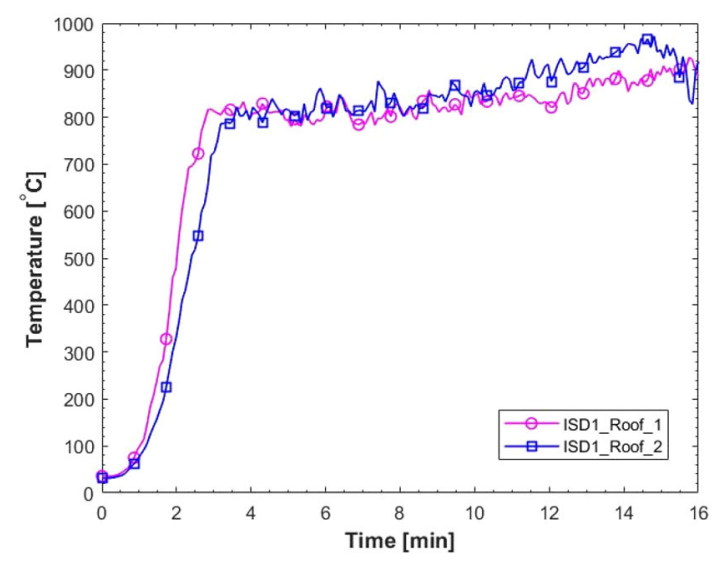

\section{Figure 17. Ceiling temperatures for ISD 1.}

ISD1. Figure 6 depicts both the location of the scales and the location of the ceiling thermocouples.

In this case, the calculated ventilation-controlled HRR is lower than the maximum HRR measured during the experiments. This most likely implies that some amount of leakage was still present during the experiment and that the ceramic blanket did not act as a perfectly impermeable material, as discussed for Exp 1 . The maximum recorded HRR in ISD1 and ISD2 were 7.9 MW (for an extremely short-lived peak) and 7.9 MW (before collapse), respectively. Although, these peaks are extremely short and it is clear that the average MLR of ISD1 is lower than that of ISD2. The average ceiling temperature of ISD1 during the fully developed stage (between $4 \mathrm{~min}$ and $16 \mathrm{~min}$ ) was $856^{\circ} \mathrm{C}$ and the maximum recorded ceiling temperature was $966^{\circ} \mathrm{C}$.

Figure 18a-d depict the front left, front right, back left and back right thermocouple tree readings, respectively. The positions of the thermocouple trees are depicted in Fig. 6 and the spacings are the same as for Exp 1. As mentioned earlier, the sudden dips in temperatures across the height of the $\mathrm{TC}$ trees are as a result of the steel cables falling to ground level. Unfortunately, the charring of the timber resulting in the screws pulling out. Hence, temperatures after the trees falling are not depicted. Ignition shown on all graphs below references to the ignition of the cardboard lining and not the exposed timber frames.

The flow fields at the window and door were also captured with bidirectional flow probes and are depicted in Fig. 19a and b, respectively. It should be noted that the delay in gas flow through the window is as a result of the installed glass in the opening. Thus, looking at Fig. 19a, there is no flow through the window when the fully developed stage was reached. However, within approximately 1 min the glass window broke and flow started as one would expect, as depicted in Fig. 19a.

Considering the door velocities between $11 \mathrm{~min}$ and $15 \mathrm{~min}$ the neutral plane is around $900-1000 \mathrm{~mm}$, with some fluctuations which is most likely as a result of 


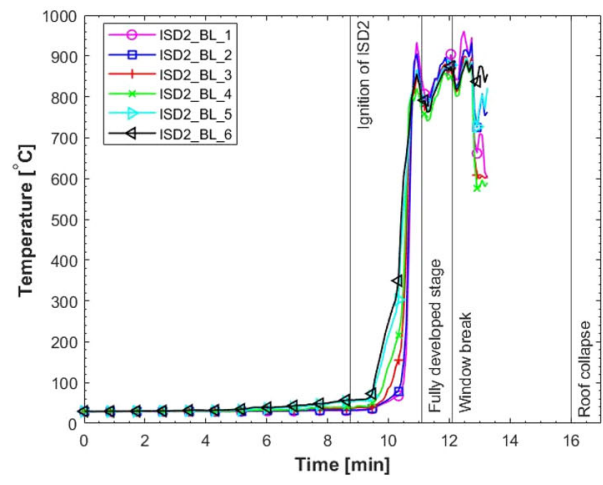

(a) Back left thermocouple tree

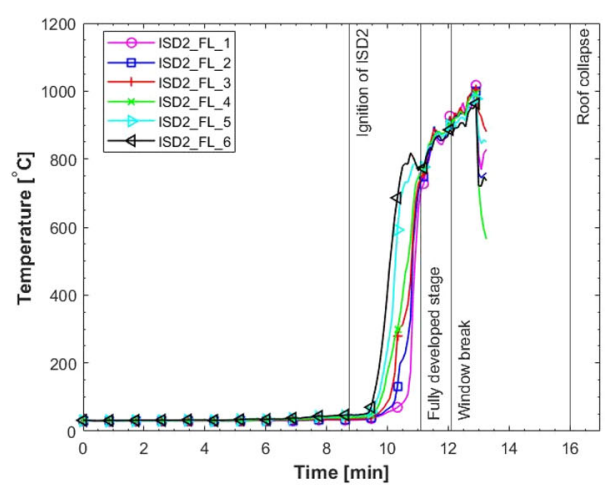

(c) Front left thermocouple tree

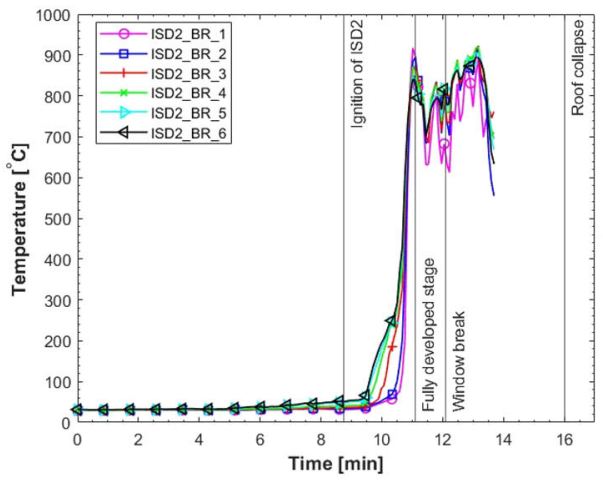

(b) Back right thermocouple tree

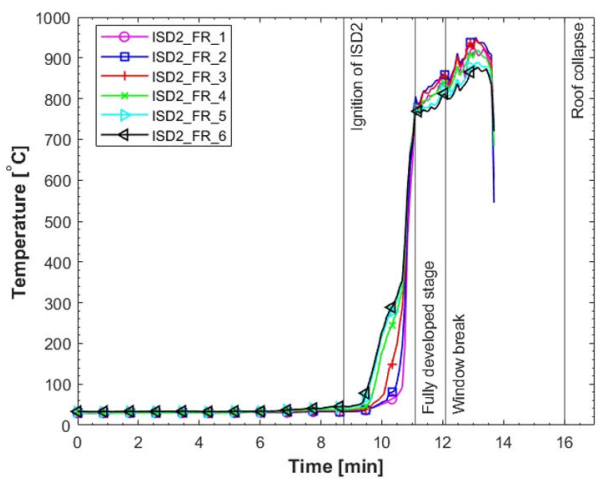

(d) Front right thermocouple tree

\section{Figure 18. a Back left thermocouple tree, b back right thermocouple tree, c Front left thermocouple tree, d Front right thermocouple tree.}

the wind (Fig. 2). This is very similar to the calculated neutral plane of $940 \mathrm{~mm}$, as for Exp 1 above (i.e., using Eq. 11).

Figure 20a depicts the incident radiation measured at the left wall of ISD2 at flute height. Figure $20 \mathrm{~b}$ depicts the incident radiation measured at the RW at a height of $2 \mathrm{~m}, 2 \mathrm{~m}$ away from the window at a height of $1.8 \mathrm{~m}$ and $4 \mathrm{~m}$ away from the window at a height of $1.8 \mathrm{~m}$. For the locations of the TSCs refer to Fig. 6.

The heat fluxes measured at 1.5 meters away from the door (Fig. 20b) is similar to the heat fluxes measured by previous researchers $[3,16]$. The average incident heat flux onto the left wall of ISD2 (Fig. 20b), during the fully developed stage of ISD1 until ignition of ISD2 was approximately $27 \mathrm{~kW} / \mathrm{m}^{2}$. The RW, $2 \mathrm{~m}$ from the window of ISD2 and $4 \mathrm{~m}$ from the window of ISD reached a maximum heat flux of $52 \mathrm{~kW} / \mathrm{m}^{2}, 23 \mathrm{~kW} / \mathrm{m}^{2}$ and $13 \mathrm{~kW} / \mathrm{m}^{2}$ (before $16 \mathrm{~min}$ ), respectively. 

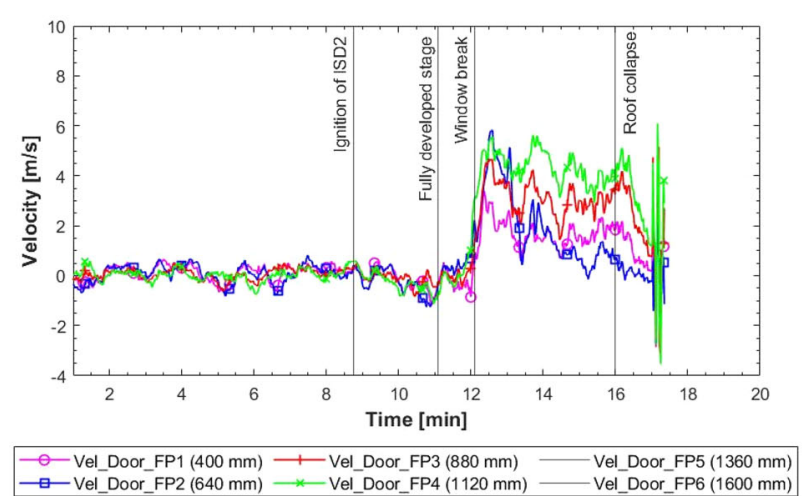

(a) Velocity readings at the window of ISD2

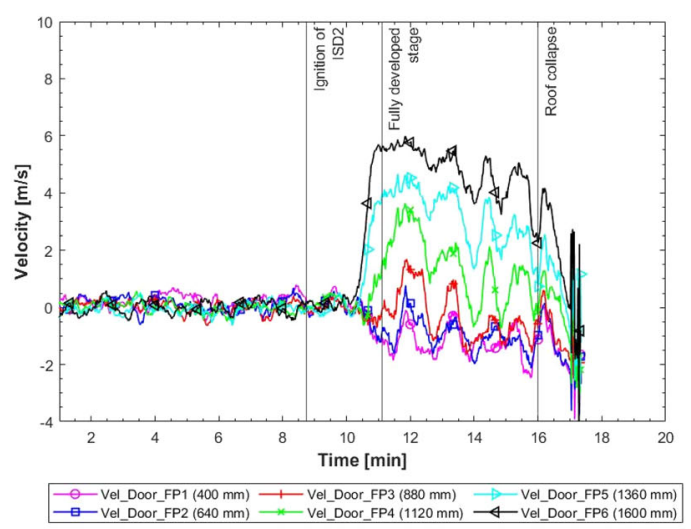

(b) Velocity readings at the door of ISD2

\section{Figure 19. a Velocity readings at the window of ISD2, b velocity readings at the door of ISD2.}

\subsection{Comparison Between Experiments: Discussion and Analysis}

Table 1 provides a summary of important parameters pertaining to both experiments, specifically those parameters and readings effecting and affected by separation distance, such as time-to-ignition of ISD2, time to flashover after ignition of ISD2, and the average heat fluxes emitted, by ISD2, during the fully developed stage. All incident heat fluxes listed are average heat fluxes during the fully-developed fire stage (until structural collapse), except for the average incident heat flux onto ISD2, which is the average between the fully developed stage of ISD1 and ignition of ISD2.

It is clear that an increase in separation distances leads to a decrease in the average heat flux emitted onto ISD2 (i.e. $33 \mathrm{~kW} / \mathrm{m}^{2}$ at $1 \mathrm{~m}$ to $27 \mathrm{~kW} / \mathrm{m}^{2}$ at $1.75 \mathrm{~m}$ ), which results in a slower time-to-ignition. It should also be noted that ISD1 of Exp 2 reached a fully developed fire stage slightly faster than that of Exp1, implying that the time-to-ignition of ISD2 for Exp 2 is actually slightly 


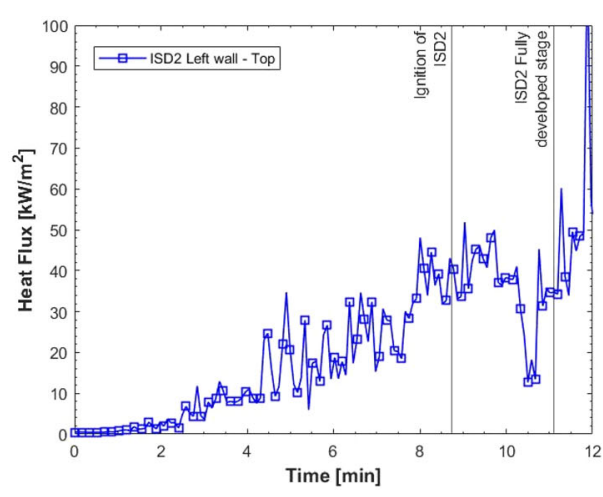

(a) Incident heat flux at the left walls of ISD2 at flute height

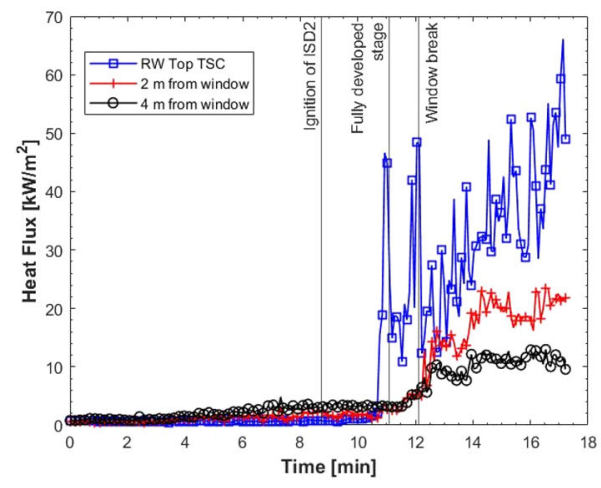

(b) Incident heat fluxes in front of openings of ISD2

\section{Figure 20. a Incident heat flux at the left walls of ISD2 at flute height, b incident heat fluxes in front of openings of ISD2.}

\section{Table 1}

Summary of Results Pertaining to Fire Spread for Exp 1 and Exp 2

\begin{tabular}{lcc}
\hline & $\begin{array}{c}\text { Experiment } \\
1\end{array}$ & $\begin{array}{c}\text { Experiment } \\
2\end{array}$ \\
\hline Separation distance & $1.0 \mathrm{~m}$ & $1.75 \mathrm{~m}$ \\
Average incident heat flux onto ISD2 & $33 \mathrm{~kW} / \mathrm{m}^{2}$ & $27 \mathrm{~kW} / \mathrm{m}^{2}$ \\
Time-to-ignition of ISD2 from the start of the fully developed stage in & $1.2 \mathrm{~min}$ & $5.45 \mathrm{~min}$ \\
$\quad$ ISD1 & $2.8 \mathrm{~min}$ & $2.35 \mathrm{~min}$ \\
Time to fully developed stage of ISD2 after ignition of ISD2 & $22 \mathrm{~kW} / \mathrm{m}^{2}$ & $19 \mathrm{~kW} / \mathrm{m}^{2}$ \\
Average incident heat flux 2 m from window & $14 \mathrm{~kW} / \mathrm{m}^{2}$ & $11 \mathrm{~kW} / \mathrm{m}^{2}$ \\
Average incident heat flux 4 m from window & &
\end{tabular}

more slower than that of Exp 1. The increase in separation distance from $1 \mathrm{~m}$ to $1.75 \mathrm{~m}$ had no noticeable effect on the time from ignition of ISD2 to flashover in ISD2. One would expect that the cardboard would preheat faster when closer to the fire source, hence leading to more rapid spread across the surface once ignited. However, from the results, this does not seem to be the case. The heat fluxes emitted from the window of ISD2 for Exp 2 are slightly less than that of Exp 1. It can relatively easily be seen that the contribution of ISD1 to the heat flux readings measured in front of the window decreases as ISD2 moves further away from ISD1. 


\section{Analytical Equations Describing Spread Rates}

In order to calculate the spread rate between ISDs, two distinct phenomena need to be calculated: (a) the incident radiation, i.e., the radiation received by the target dwelling from an emitting surface(s) (the adjacent dwelling burning), and (b) the time-to-ignition of the target dwelling given the incident radiation described in (a). In this case, ignition is assumed to be piloted ignition, because during the experiments flame impingement was observed. Additionally, convective cooling is ignored, as it is assumed to only have a small effect on the time-to-ignition. This is a conservative assumption should this method be implemented in a large-scale simulation, for example if used in a Monte Carlo simulation, since convective cooling will slightly slow the time-to-ignition. The assumptions of convective cooling and piloted ignition are discussed in more detail in the sections that follow. The spread rates are now calculated, using the experimental data for validation.

To estimate the radiation received by, for example the left wall of ISD2, the components of ISD1 that radiates onto ISD2 should first be identified. The radiation received by ISD2 $\left(\dot{q}_{i n c}^{\prime \prime}\right)$ will thus be a sum of: (1) the radiation received from the hot compartment gases of ISD1 (denoted as $\dot{q}_{\text {comp_gas }}^{\prime \prime}$ ); (2) the radiation received from the flames ejecting from the door of ISD1 (denoted as $\dot{q}_{\text {flame }}^{\prime \prime}$ ); and (3) the radiation received from the galvanized steel sheets of ISD1 (denoted as $\dot{q}_{\text {sheets }}^{\prime \prime}$ ). The mathematical equation for the incident radiation from ISD1 and the configuration factors used below are discussed in detail in "Appendix 2", where ISD1 can be seen as the burning dwelling in "Appendix 2", and ISD2 can be seen as the target dwelling in "Appendix 2".

\subsection{Incident Radiation: Compartment Gases}

The radiating surface of the hot gases will take the shape of the door opening of ISD1. Hence, the integration should be over the surface of the door. Using the coordinate system depicted in Fig. 33 (see "Appendix 2"), Equation (16) in "Appendix 2" now looks as follows:

$$
\emptyset=\int_{0}^{2.05} \int_{1}^{1.85} \frac{\cos \theta_{1} \cos \theta_{2}}{\pi r^{2}} \cdot d y_{1} \cdot d z_{1}
$$

By substituting $y_{2}=1.45 \mathrm{~m}, z_{2}=2.3 \mathrm{~m}$ and $s=1 \mathrm{~m}$ into Eq. (1) and solving the integrals in Matlab yields $\emptyset=0.13$. Since the height and width of a door is relatively standard, only the separation distance is varied in Fig. 21. This provides a brief parametric study useful for understanding the influence of the separation distance on the radiation received by ISD2 (at $y_{2}=1.45 \mathrm{~m}$ and $z_{2}=2.3 \mathrm{~m}$ ) from the hot compartment gases.

Figure 21 shows that as the separation distance decreases, the configuration factor decreases approximately exponentially, implying that the incident heat flux would also decrease exponentially (the minimum distance of $0.5 \mathrm{~m}$ is an approximation of the minimum external dimensions out of a door). 


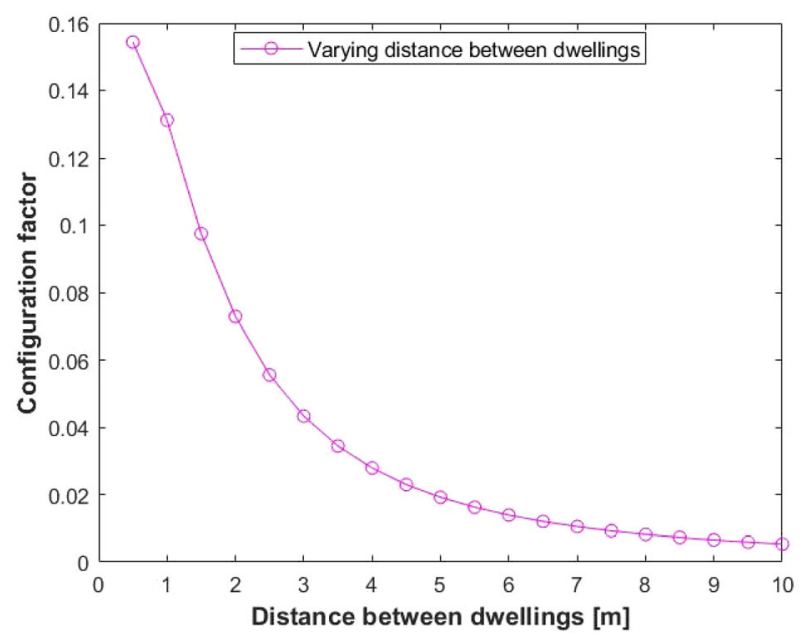

\section{Figure 21. Configuration factor of the door openings for various separation distances.}

Using the average temperature of the hot layer as measured in both Exp 1 and Exp 2 during the fully developed fire stage of ISD 1 as $879^{\circ} \mathrm{C}$, assuming the emissivity of the compartment gases is equal to $1[17,21]$, and the configuration factor of 0.13 , the incident radiation due to the compartment gases is calculated as $13.1 \mathrm{~kW} / \mathrm{m}^{2}$ (using only the part of Equation (12) that applies to the compartment gases).

\subsection{Incident Radiation: Flame}

The configuration factor of the flames can be calculated by making some assertive assumptions. Firstly, it is assumed that the flames ejecting from the door only starts at the height of the neutral plane $[0.79 \mathrm{~m}$ for ISD1, as calculated using Eq. (11)], secondly it is assumed that the width of the flame is approximately equal to the width of the door, and lastly, it is assumed that the height of the flames are equal to the average recorder flame height ( $2.5 \mathrm{~m}$ from video footage), i.e., during the fully developed stage. Equation (16) now looks as follows:

$$
\emptyset=\int_{0.79}^{2.5} \int_{1}^{1.85} \frac{\cos \theta_{1} \cos \theta_{2}}{\pi r^{2}} \cdot d y_{1} \cdot d z_{1}
$$

By substituting $y_{2}=1.45 \mathrm{~m}, z_{2}=2.3 \mathrm{~m}$ and $s=1 \mathrm{~m}$ into Eq. (2) and solving the integrals in Matlab yields $\emptyset=0.23$. It should be noted here that in this case it was assumed that $s$ is from ISD1 to ISD2, but in reality, $s$ should be taken from the center or edge of the flame. This however significantly complicates the equation and would lead to even more assumptions. That is, since the center of the flame varies with height and since the flame also fluctuates in height and length in real- 
ity. Hence, this would require more assumptions and would be less functional should this method be employed in a Monte Carlo-type simulation in the future. This assumption is slightly unconservative. Assuming the height and width of the flame remains relatively constant, and only varying the separation distance, Fig. 22 is obtained.

From Fig. 22, it is interesting to see that the configuration almost reduces to zero at approximately $4 \mathrm{~m}$ away from ISD1, implying that the external flame has virtually no effect on the incident radiation if the target is $4 \mathrm{~m}$ away from the burning dwelling. It should be noted that this is only the case for ignition at a height of $z_{2}=H$. For other target heights, the configuration factor will change.

Using the average temperature of the door flames (measured at ISD2 next to each FP), as measured in both Exp 1 and Exp 2 during the fully developed fire state of $892^{\circ} \mathrm{C}$ (unfortunately the flame temperatures at the door of ISD1 were not measured, but it was measured at the door of ISD2, hence as a best alternative, it is assumed that the door flame temperatures for ISD1 and ISD2 are similar). Thus, the average temperature as measured by the FP thermocouples at the door of ISD2 for bot Exp 1 and Exp 2 are used here, assuming the emissivity of the flames is equal to $1[17,21]$ (which is a conservative assumption), and the configuration factor of 0.23 , the incident radiation due to the door flames is calculated as $23.6 \mathrm{~kW} / \mathrm{m}^{2}$ (using only the part of Eq. (12) that applies to the door flames).

\subsection{Incident Radiation: Sheets}

One can assume that the configuration factor for the IBR sheeting of the right wall of ISD1 (Fig. 31) is approximately the same as the configuration of IBR sheeting of right wall of ISD1, if the right wall of ISD1 had no door and was fully cladded with IBR sheeting minus the configuration factor of the door alone. Additionally, for simplicity, it has been assumed that the IBR acts as a flat emitter (i.e., the IBR does not have a corrugated surface but acts as a flat plate). Substituting $y_{2}=1.45 \mathrm{~m}, z_{2}=2.3 \mathrm{~m}, H_{r}=2.3 \mathrm{~m}, L_{r}=3.6 \mathrm{~m}$ and $s=1 \mathrm{~m}$ into Eq. (16) and solving the integrals in Matlab yields $\emptyset=0.41$ (i.e., the configuration factor of the right wall with no door). Figure 23 shows the configuration for a variety of separation distances, dwelling heights and dwelling lengths. This provides a brief parametric study useful for understanding the influence of the emitter's geometry.

Figure 23 clearly shows the effect of the spacing between dwellings. The configuration factor can be halved by just increasing the separation distance from $1 \mathrm{~m}$ to $2.7 \mathrm{~m}$. Figure 23 also immediately highlights the danger of double storey informal settlement dwellings. Increasing the dwelling height from $2.5 \mathrm{~m}$ (single storey) to $5 \mathrm{~m}$ (double storey) leads to a $64.8 \%$ increase in configuration factor.

The configuration factor of the IBR sheeting of the right wall of ISD1 can be approximated as:

$$
\emptyset_{\text {ISD1sheeting }}=\emptyset_{\text {fullyclad }}-\emptyset_{\text {door }}=0.41-0.13=0.28
$$




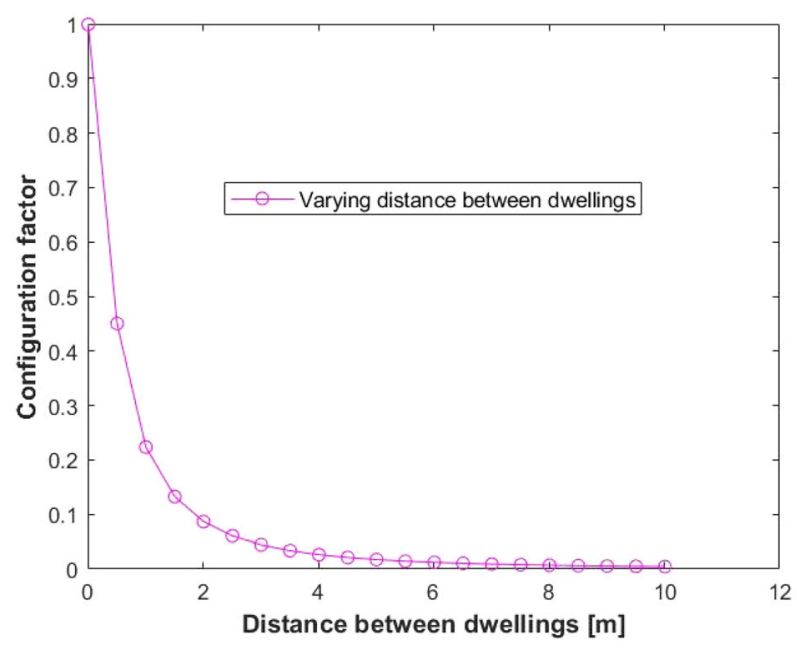

\section{Figure 22. Configuration factor of the door flames for various separation distances.}

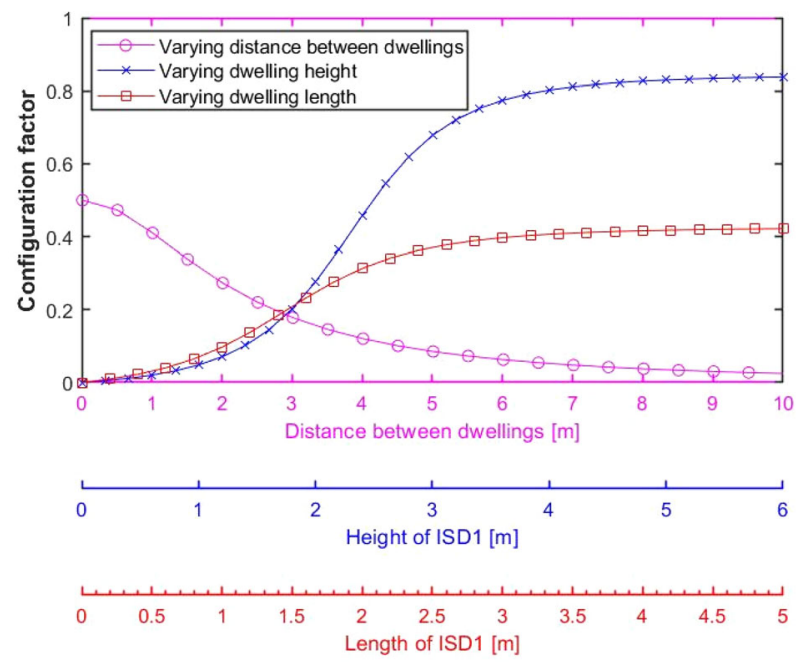

Figure 23. Configuration factor of the IBR sheeting for various separation distances, dwelling heights and dwelling lengths.

Using the average temperature the IBR sheeting, as measured in both Exp 1 and Exp 2 during the fully developed fire stage of ISD 1 as $585^{\circ} \mathrm{C}$ (where the measured temperatures of these experiments are relatively constant across the height of the dwelling), assuming the emissivity of the galvanized sheeting is equal to 0.32 (i.e., $0.22-0.28$ for galvanized steel at $0-200^{\circ} \mathrm{C}$ [22] and 0.42 for galvanized steel at $1400^{\circ} \mathrm{C}$ [22] $)$, thus assuming $0.2567+(0.42-0.28) /(1400-200) \times 585=0.32$ 
for galvanized steel at $585^{\circ} \mathrm{C}$ ), and the configuration factor of 0.28 , the incident radiation due to the steel sheets is calculated as $3 \mathrm{~kW} / \mathrm{m}^{2}$ (using only the part of Eq. (13) that applies to the IBR sheets).

\subsection{Incident Radiation: Comparison}

Based on the equations derived in "Appendix 2" and those used in the sections above, Figure 24 shows the contribution of each of ISD1's radiating surfaces (components). It is clear that the flames from the door has a substantial effect on the total incident radiation and that the radiation from the sheets is almost negligibly small compared to the other components. Since the radiation emitted by the flame has such a dominant impact on calculations, the factors which affect its behavior most are of importance. During the experiments the wind did affect the flame orientation, although with the pulsating flame effect it is difficult to exactly quantify the effects of the wind. If the flame tilts towards the target ISD it will result in higher radiation, and a reduced time-to-ignition. This requires further research and the inclusion of methodologies to account for the influence of wind.

\subsection{Time-to-Ignition}

Over the past few decades a significant amount of research [23-25] has focused on the development of correlations between time-to-ignition and incident radiation data for combustible materials, where most correlations are developed from Cone Calorimeter data. These correlations are generally based on a theoretical model of heat conduction into an inert solid as a result of the incident radiation and the losses due to radiation and convection to varying degrees of complexity. Comparing all the time-to-ignition methods is outside the scope of this work, however, a number of researchers have summarized these different correlations and it is available in the literature should the reader require further information [26-28]. Based on work done by Baker et al. [29], it was decided to use the Flux-Time Product (FTP) method to determine the time-to-ignition in this work. For piloted ignition of combustible materials, the FTP method is a simplified way to predict time-toignition of the material under a time-varying incident radiation $\left(\dot{q}_{i n c}^{\prime \prime}\right)$. The theory behind the FTP method is that the FTP value of a material exposed to an external heat flux (that is greater that the critical heat flux (CHF) of the material) accumulates until it exceeds a threshold value at which point the material ignites. The method was originally derived by Smith and Satjia [24], which other researchers further developed upon. The method was then generalized by Shields et al. [21] such that:

$$
F T P=t_{i g}\left(\dot{q}_{i n c}^{\prime \prime}-\dot{q}_{c r}^{\prime \prime}\right)^{n}
$$

where $t_{i g}$ is the time-to-ignition (s), $\dot{q}_{i n c}^{\prime \prime}$ is the incident heat flux $\left(\mathrm{kW} / \mathrm{m}^{2}\right)$ [as calculated using Eq. (12)], $\dot{q}_{c r}^{\prime \prime}$ is the critical heat flux $\left(\mathrm{kW} / \mathrm{m}^{2}\right)$, and FTP index $(n)$ is obtained by iteratively varying $n$ to get the best linear fit for $1 / t_{i g}^{n}$ versus $\dot{q}_{i n c}^{\prime \prime}$. In this case, the only materials of importance are the timber used for the frames of 


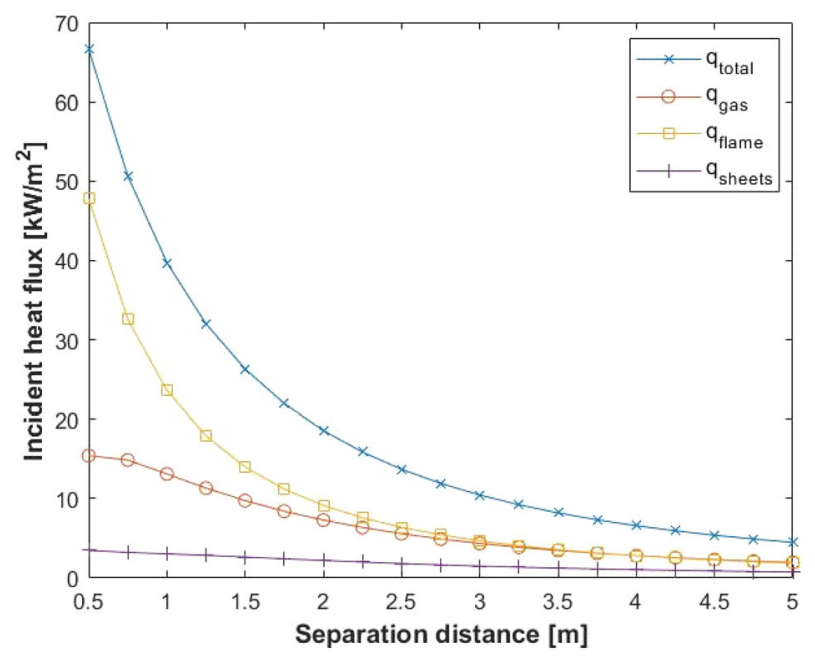

\section{Figure 24. Incident radiation comparison of the different radiation sources from ISD 1.}

the ISDs and the cardboard used for internal lining. Piloted ignition measurements from the cone calorimeter experiments for both the cardboard and timber used in the large-scale experiments can be seen in Fig. 25. By varying $n$, the trendline with the highest correlation factor $\left(R^{2}\right)$ can be obtained. In this case, the $n$ value that gave the best correlation for the cardboard and timber are $n=1.1$ and $n=1.6$, respectively. The gradients of the trendlines are equal to the respective $F T P^{1 / n}$ values and the y asymptotes can be assumed to be the CHF of the materials.

As mentioned earlier, when a material is exposed to an external heat flux, the FTP value accumulates until it exceeds a threshold value at which point the material ignites. The mathematical formulation that describes this is a variant on Eq. (4) such that for every time step when $\dot{q}_{i n c}^{\prime \prime}$ exceeds $\dot{q}_{c r}^{\prime \prime}$, the FTP value is calculated in a cumulative fashion:

$$
F T P=\sum_{i=1}^{m}\left(\dot{q}_{i n c}^{\prime \prime}-\dot{q}_{c r}^{\prime \prime}\right)^{n} \Delta t_{i}
$$

where $\Delta t_{i}$ is the $i$ th time increment.

Using the actual incident heat flux recorded at a height of $2.3 \mathrm{~m}$ the door of ISD1 for Exp 1 and Exp 2, the time-to-ignition can be predicted using Eq. (5). Figure 26a and $\mathrm{b}$ depicts the cumulative FTP value as a function of time for Exp 1 and Exp 2, respectively. Note that since the timber frame is the material exposed to the radiation and the material that ignited first, in this section the FTP and $n$ values used are the values of the timber. Additionally, the time-to-ignition in this case will be the time-to-ignition of the timber and not the cardboard as used in the sections above. 


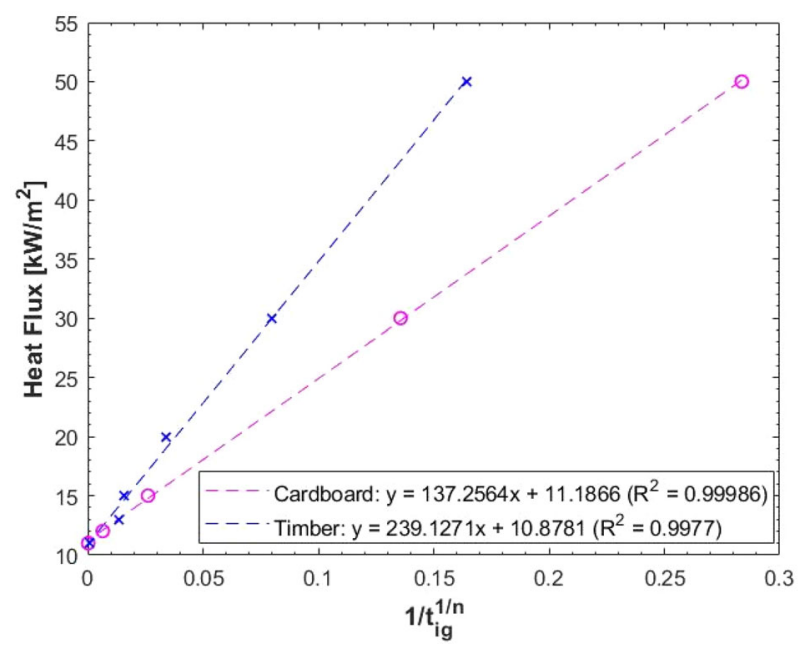

\section{Figure 25. Correlation of ignition times and incident heat flux (cone calorimeter data from [35, 36]).}

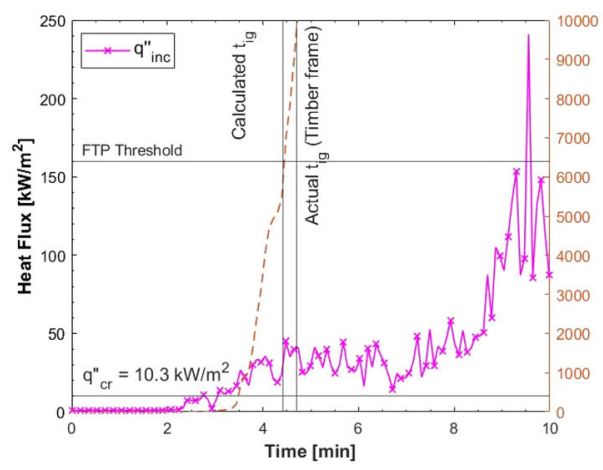

(a) Calculated time-to-ignition for Exp1 using the cumulative FTP method

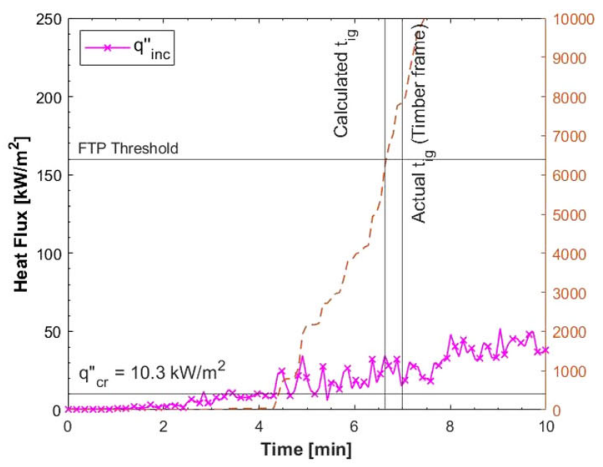

(b) Calculated time-to-ignition for Exp2 using the cumulative FTP method

\section{Figure 26. a Calculated time-to-ignition for Exp 1 using the cumulative FTP method, b Calculated time-to-ignition for Exp2 using the cumulative FTP method.}

From Fig. 26a and b (dwellings spaced at $1 \mathrm{~m}$ and $1.75 \mathrm{~m}$, respectively) it can be seen that the FTP method slightly underpredicts (faster) the time-to-ignition by $6.3 \%$ and $6 \%$, respectively. In both instances the calculated time-to-ignition deviates less than $7 \%$ of the actual time-to-ignition, implying that the correlation between the FTP method and reality is good. For further distances, the cooling effects of the wind might cause larger deviations, but since these dwellings are typically spaced at closed proximities this method is suitable. It should also be noted that if the spacing between dwellings become large, the assumption of piloted ignition might not hold, and thus adjustments should be made to Eq. (5). Baker et al. 
[30] discusses the alterations needed to account for auto ignition should the reader require further information, it is however not in the scope of this paper.

\subsection{The Effect of the Distance(s) Between the Emitter and Receiver on Spread Rates}

Given the temperatures and emissivity of the compartment gasses, flames and the IBR sheeting, the time-to-ignition can be calculated at various separation distances. The average temperatures of the hot layer, the IBR sheeting and the door flames, as measured for both Exp 1 and Exp 2 during the fully developed fire stage of ISD1 are $879^{\circ} \mathrm{C}$ (unfortunately the flame temperatures at the door of ISD1 were not measured, hence as a best alternative, it is assumed that the door flame temperatures for ISD1 and ISD2 are similar. Thus, the temperature as measured by the FP thermocouples at the door of ISD2 are used here), $585^{\circ} \mathrm{C}$ (where the measured temperatures of these experiments are relatively constant across the height of the dwelling) and $892^{\circ} \mathrm{C}$, respectively. Assuming the emissivity of the flames and compartment gases are equal to 1 [31, 32], and that the emissivity of the galvanized sheeting is equal to 0.35 (i.e., $0.22-0.28$ for galvanized steel at 0 $200^{\circ} \mathrm{C}$ [22] and 0.42 for galvanized steel at $1400^{\circ} \mathrm{C}$ [22], thus assuming $0.2567+(0.42-0.28) /(1400-200) \times 585=0.32$ for galvanized steel at $585^{\circ} \mathrm{C}$, as discussed above). Substituting the knowns (i.e., calculating the configuration factor as per above, $F T P=6390$ and $n=1.6$ ) into Eqs. (12), (16) and (4) the time-to-ignition can be calculated for a variety of separation distances.

From Fig. 27, it is clear that the separation distance plays a significant role in the time-to-ignition. At a separation distance of $2.5 \mathrm{~m}$, the calculations show that it would take an adjacent dwelling (built with timber and lined with cardboard) approximately $35 \mathrm{~min}$ to ignite. It can thus be said that there is a vertical asymptote at $2.9 \mathrm{~m}$ separation distance in this case. Hence, giving the input parameters above (i.e., for these specific dwellings), fire will not spread if there is a separation distance greater or equal to $2.9 \mathrm{~m}$. At $1 \mathrm{~m}$, Fig. 27 shows a heat flux of $39 \mathrm{~kW} / \mathrm{m}^{2}$ which is slightly greater than the measured heat flux at $1 \mathrm{~m}$ for Exp 1 of $33 \mathrm{~kW} /$ $\mathrm{m}^{2}$. At $1.75 \mathrm{~m}$, Fig. 27 shows a heat flux of $22 \mathrm{~kW} / \mathrm{m}^{2}$ which is slightly smaller than the measured heat flux at $1.75 \mathrm{~m}$ for Exp 2 of $27 \mathrm{~kW} / \mathrm{m}^{2}$. Thus, showing that the calculated heat fluxes are slightly more susceptible to the separation distance compared to the experiments. This could however be as a result of factors such as the assumed integration limits [Eq. (16)] and might be different from fire scenario to fire scenario, but with all the variables and unknowns, these calculations show promise for future use. With the high variability inherent with ISDs a robust, but simple, method may be preferable to a more advanced model that requires additional input parameters for those wishing to apply this in practice.

For interest, the effect of the ignitable material height and the $\mathrm{CHF}$ of the ignition source on the critical separation distance are depicted in Fig. 28a and b, respectively. It is clear that the CHF can significantly increase or decrease the critical separation distances needed for fire spread not to occur. Increasing the CHF from $10 \mathrm{~kW} / \mathrm{m}^{2}$ (as in this case) to $15 \mathrm{~kW} / \mathrm{m}^{2}$, reduces the critical separation distance needed from approximately $2.8 \mathrm{~m}$ to $2.1 \mathrm{~m}$. From Fig. 28a it appears that 


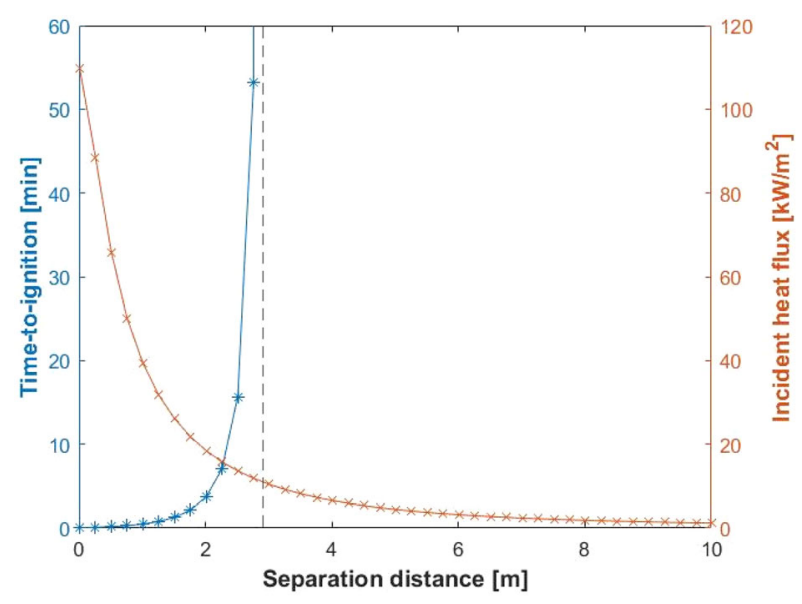

Figure 27. The effect of separation distance on time-to-ignition.

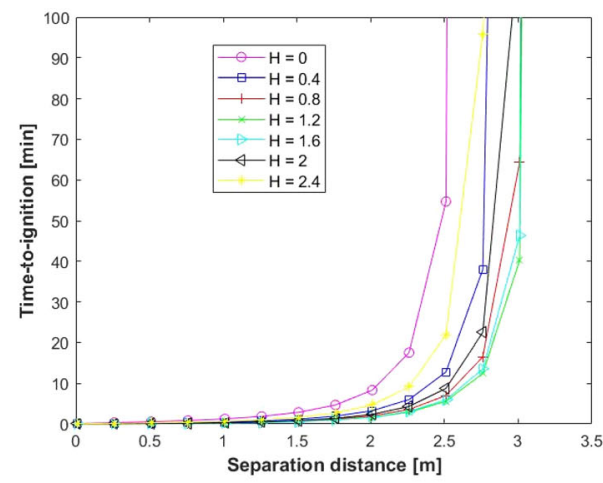

(a) Effect of ignition source height of critical separation distance

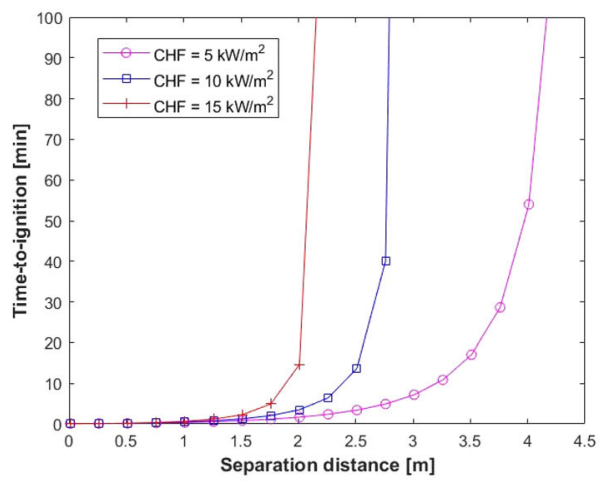

(b) Effect of CHF on critical separation distance

\section{Figure 28. a Effect of ignition source height of critical separation distance, b Effect of CHF on critical separation distance.}

the most critical positions are in the middle of the target dwelling and as the point of ignition moves up or down the height of the dwelling, the received radiation becomes less. However, combustibles closer to floor level would not necessarily have flame impingement, thus requiring a higher incident heat flux for spontaneous ignition.

\section{Conclusion}

In this work, the effects of dwelling separation distance and dwelling parameters on fire spread rates have been investigated. Two full-scale informal settlement dwelling fire experiments, consisting of two dwellings each, were conducted. The 
main difference between the two experiments was the dwelling separation distance. From the experimental results, it is clear that an increase in separation distance drastically increased the time-to-ignition, i.e., $5.5 \mathrm{~min}$ for dwellings spaced at $1 \mathrm{~m}$ compared to $8.75 \mathrm{~min}$ for dwellings spaced at $1.75 \mathrm{~m}$. The paper continued by using robust and fundamental equations to determine (1) the neutral planes of these dwellings, (2) the incident radiation emitted from these dwellings, and (3) the time-to-ignition of a target dwelling, subjected to the radiation from an adjacent burning dwelling. Using these analytical equations, it was found that:

- the time-to-ignition increases approximately exponentially as the separation distance between dwellings increases (as might be expected);

- taller dwellings emit more radiation compared to shorter dwelling;

- the FTP method had less than a 7\% deviation compared to reality; and

- that the $\mathrm{CHF}$ of the exposed combustibles of the target dwelling could drastically increase or decrease the critical separation distance needed for fire spread not to occur.

The radiation and time-to-ignition methods developed in this work are currently being used as a basis for developing a semi-probabilistic modelling approach for fire spread for informal settlements. The model developed approximates the timeto-ignition within $7 \%$ of the experimental results, under-predicting ignition times for each experiment. It is noted that the radiation emitted by the flame has a dominant effect on the total heat flux on the target ISD. Hence, further research is required to include the effect of wind as it is likely to have an influence on the calculations.

Further work is required to study the influence of factors such as different cladding materials, combustible dwellings, and the influence of wind on both flame length and convective cooling of the target dwelling. The model developed could also be used to study the influence of the difference in height of structures, to begin accounting for the influence of topography. Some ignition mechanisms, such as ember attack in ISDs, require significant research as minimal data is available, but would be needed in models in conjunction with the work proposed in this paper, to capture real spread behavior.

\section{Acknowledgements}

The authors would like to gratefully acknowledge Breede Valley Fire Department, especially Mr JJ Pretorius and his team, and two undergraduate students, Monique Scheepers and Kyle Stebbing, from Stellenbosch University for their contribution and assistance towards helping the authors successfully complete the experiments. Also, advice from Prof Charley Fleischmann regarding the calculation of heat fluxes at a distance, which has been implemented in this work, is gratefully acknowledged. This work is financially supported by IRIS-Fire GCRF project from the UK (Engineering and Physical Sciences Research Council Grant 
No.: EP/P029582/1) and the Lloyd's Register Foundation under the "Fire Engineering Education for Africa" Project (Grant GA 100093).

\section{Open Access}

This article is licensed under a Creative Commons Attribution 4.0 International License, which permits use, sharing, adaptation, distribution and reproduction in any medium or format, as long as you give appropriate credit to the original author(s) and the source, provide a link to the Creative Commons licence, and indicate if changes were made. The images or other third party material in this article are included in the article's Creative Commons licence, unless indicated otherwise in a credit line to the material. If material is not included in the article's Creative Commons licence and your intended use is not permitted by statutory regulation or exceeds the permitted use, you will need to obtain permission directly from the copyright holder. To view a copy of this licence, visit http://creat ivecommons.org/licenses/by/4.0/.

\section{Appendix 1: Neutral Plane Calulcation}

The details provided below give the methodology employed in this paper for calculating the position of the neutral plane, through which analyses in this work are carried out. Consider Fig. 29, since the velocities across the area of the openings are not constant, the mass flow through an opening can be written as [31]:

$$
\dot{m}=C_{d} \int_{A} \rho v d A
$$

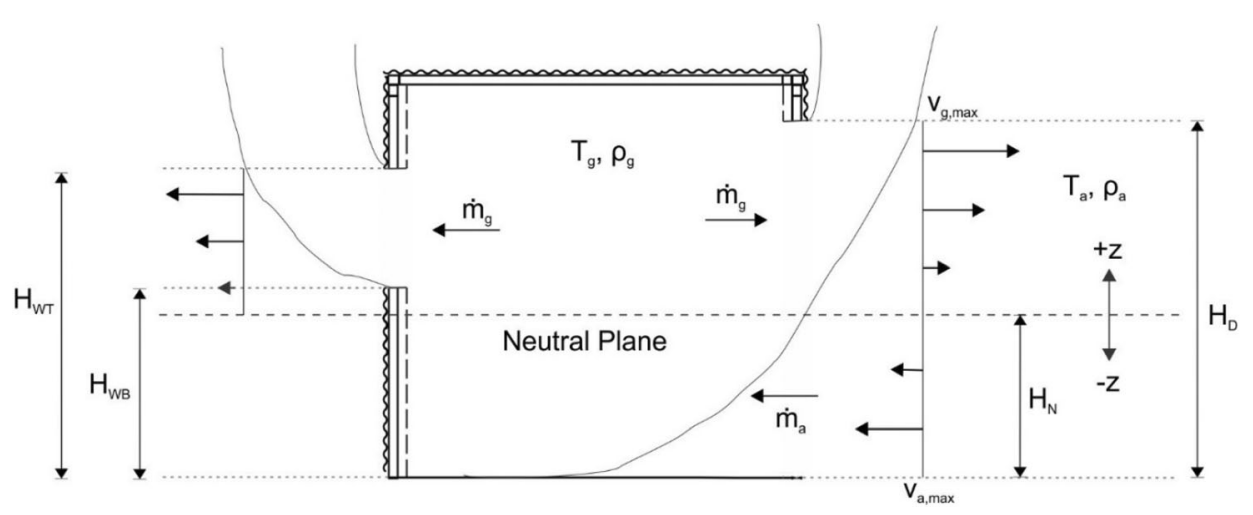

Figure 29. Notation describing the vent flows of ISD2. 
where $C_{d}$ is the flow coefficient, which is a function of the Reynolds Number, and it is typically considered to be between 0.6 and 0.7 for door- and window type openings; $\rho$ is the density of the gas; $v$ is the velocity of the gas; and $d A$ can be set to $W \cdot d z$, where $W$ is the width of the opening.

From Bernoulli's equation, the velocity as a function of the height $z$ above the neutral plane can be written as:

$$
v_{g}(z)=\sqrt{\frac{2 z\left(\rho_{a}-\rho_{g}\right) g}{\rho_{g}}}
$$

Using the actual geometry of the experiments, Eq. (6) for the mass flow rate of hot gases out of the openings can be rewritten as:

$$
\dot{m}_{g}=C_{d} \int_{H_{N}}^{H_{W T}} W_{w} \rho_{g} v_{g}(z) d z-C_{d} \int_{H_{N}}^{H_{W B}} W_{w} \rho_{g} v_{g}(z) d z+C_{d} \int_{H_{N}}^{H_{D}} W_{D} \rho_{g} v_{g}(z) d z
$$

where $W_{w}$ and $W_{D}$ is the width of the window and door, respectively. This term can be seen as the contribution of (1) a triangular velocity distribution from the neutral plane to the top of the window, minus (2) the area between the neutral plan and bottom of the window which is not open, plus (3) the contribution of the door. Solving the integrals and substituting Eqs. (7) into (8) gives:

$$
\begin{aligned}
\dot{m}_{g}= & \frac{2}{3} C_{d} W_{w} \rho_{g} \sqrt{\frac{2\left(\rho_{a}-\rho_{g}\right) g}{\rho_{g}}}\left(H_{W T}-H_{N}\right)^{\frac{3}{2}}-\frac{2}{3} C_{d} W_{w} \rho_{g} \sqrt{\frac{2\left(\rho_{a}-\rho_{g}\right) g}{\rho_{g}}}\left(H_{W G}-H_{N}\right)^{\frac{3}{2}} \ldots \\
& +\frac{2}{3} C_{d} W_{D} \rho_{g} \sqrt{\frac{2\left(\rho_{a}-\rho_{g}\right) g}{\rho_{g}}}\left(H_{D}-H_{N}\right)^{3 / 2}
\end{aligned}
$$

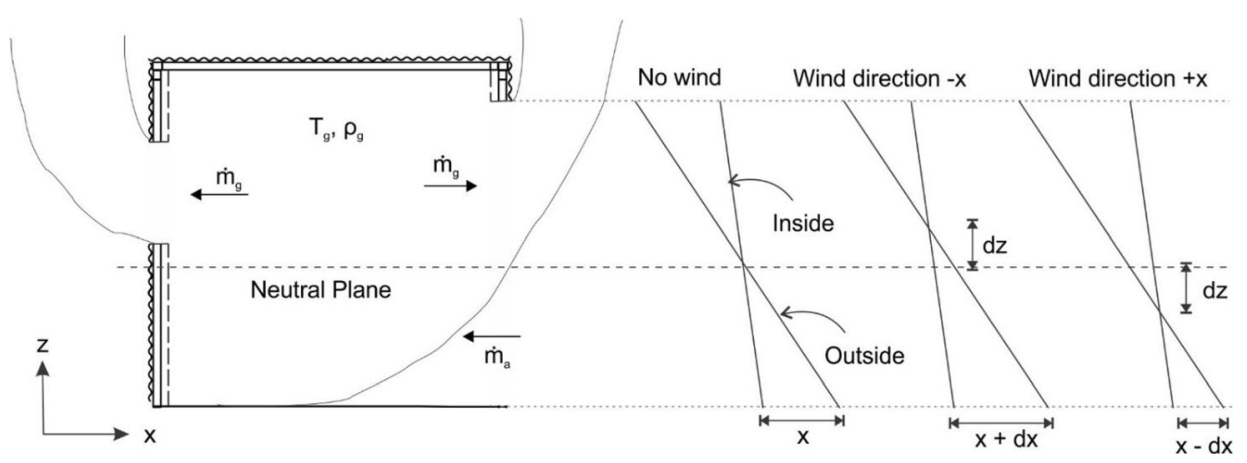

Figure 30. Effect of wind on the pressure profile of the dwelling. 
A similar process can be followed to derive the expression for the mass flow rate of cold air in through the openings, giving the following equation:

$$
\dot{m}_{a}=\frac{2}{3} C_{d} W_{D} \rho_{a} \sqrt{\frac{2\left(\rho_{a}-\rho_{g}\right) g}{\rho_{a}}}\left(H_{N}\right)^{\frac{3}{2}}
$$

Setting Eq. (9) equal to Eq. (10), yields the following:

$$
W_{w} \sqrt{\rho_{g}}\left(H_{W T}-H_{N}\right)^{\frac{3}{2}}-W_{w} \sqrt{\rho_{g}}\left(H_{W B}-H_{N}\right)^{\frac{3}{2}}+W_{D} \sqrt{\rho_{g}}\left(H_{D}-H_{N}\right)^{\frac{3}{2}}=W_{D} \sqrt{\rho_{a}}\left(H_{N}\right)^{\frac{3}{2}}
$$

Equation (11) does not account for the effects of wind. Figure 30 visually depict the effect wind will have on the neutral plane height.

\section{Appendix 2: Incident Radiation-Methodology}

The radiation received by a target dwelling $\left(\dot{q}_{i n c}^{\prime \prime}\right)$ is the sum of; (1) the radiation received from the hot compartment gases of burning dwelling (denoted as $\dot{q}_{\text {comp_gas }}^{\prime \prime}$ ); (2) the radiation received from the flames ejecting from the door of burning dwelling (denoted as $\dot{q}_{\text {flame }}^{\prime \prime}$ ); and (3) the radiation received from the galvanized steel sheets of burning dwelling (denoted as $\dot{q}_{\text {sheets }}^{\prime \prime}$ ). The radiation received then reduces as the target (the receiver) moves further away from the emitters, i.e., as a result of the configuration factor $(\emptyset)$. The mathematical equation for the three components (1-3) mentioned above is as follows:

$$
\dot{q}_{\text {inc }}^{\prime \prime}=\sigma \emptyset_{\text {comp_gas }} \varepsilon_{\text {comp_gas }} T_{\text {comp_gas }}^{4}+\sigma \emptyset_{\text {flame }} \varepsilon_{\text {flame }} T_{\text {flame }}^{4}+\sigma \emptyset_{\text {sheets }} \varepsilon_{\text {sheets }} T_{\text {sheets }}^{4}
$$

where $\sigma$ is the Stefan-Boltzmann constant $\left(5.67 \times 10^{-11} \mathrm{~kW} /\left(\mathrm{m}^{2} \mathrm{~K}^{4}\right)\right), \emptyset$ is the configuration factor between the emitting and receiving surfaces, $\varepsilon$ is the emissivity

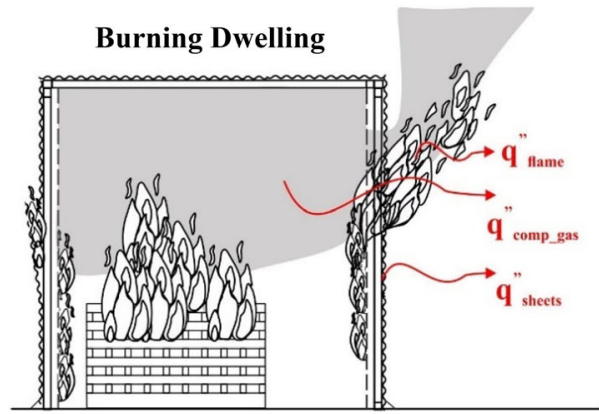

Target dwelling

Figure 31. Visual representation of the radiation emitted from the burning dwelling. 


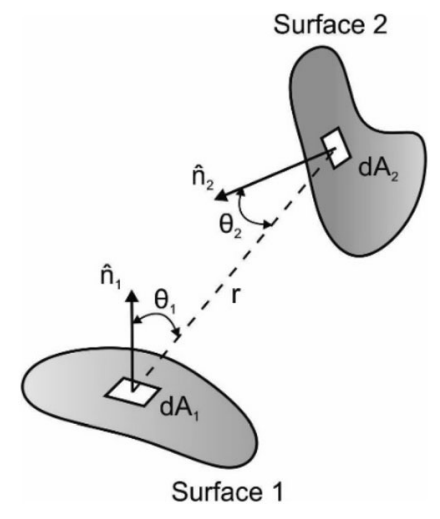

Figure 32. Derivation of the configuration factor $\varphi$ for a small
element of surface at 2 exposed to a radiating surface at 1 .

of the emitter, and $T$ is the temperature $(\mathrm{K})$ of each emitter. The three emitters contributing to the incident radiation are visually depicted in Fig. 31. It should be noted here that in this paper the incident heat flux during the fully developed stage is of interest, since it is assumed that the incident heat flux will be smaller than the critical heat flux (CHF) of the target material during pre-flashover stage [3]. Hence, for the remainder of this section, the equations derived or stipulated are specifically considered with the fully developed fire scenario in mind. For simplicity, it has been assumed that the dwelling behaves as a one-zone scenario, i.e., that the temperature throughout the compartment is the same and that the temperature does not vary across the height of the compartment. This was observed during these experiments, as shown in the thermocouple tree data depicted in the paper, and was also observed in previous ISD experiments $[6,33]$. This immediately simplifies the complexity of Eq. (12) and the temperature of each emitter can thus be taken as the average measured temperature of the specific radiator (emitter) under consideration during the fully developed fire stage.

For problems related to ignition, a finite-to-infinitesimal area configuration factor can be used, which is described by the following equation [34]:

$$
\emptyset=\int_{0}^{A_{1}} \frac{\cos \theta_{1} \cos \theta_{2}}{\pi r^{2}} \cdot d A_{1}
$$

where $A_{1}$ is the area of surface 1 and $\theta_{1}$ (or $\theta_{2}$ ) is the angle between the surface normal $\hat{\mathrm{n}}_{1}$ (or $\hat{\mathrm{n}}_{2}$ ) and the line connecting $d A_{1}$ to $d A_{2}$ (of length r). Figure 32 visually depicts the variables of Eq. (13).

Assuming that the normal vectors are always parallel to each other (Fig. 33), the distance between the two infinitesimal areas $(r), \cos \theta_{1}$ and $\cos \theta_{2}$ can then be written as follows: 


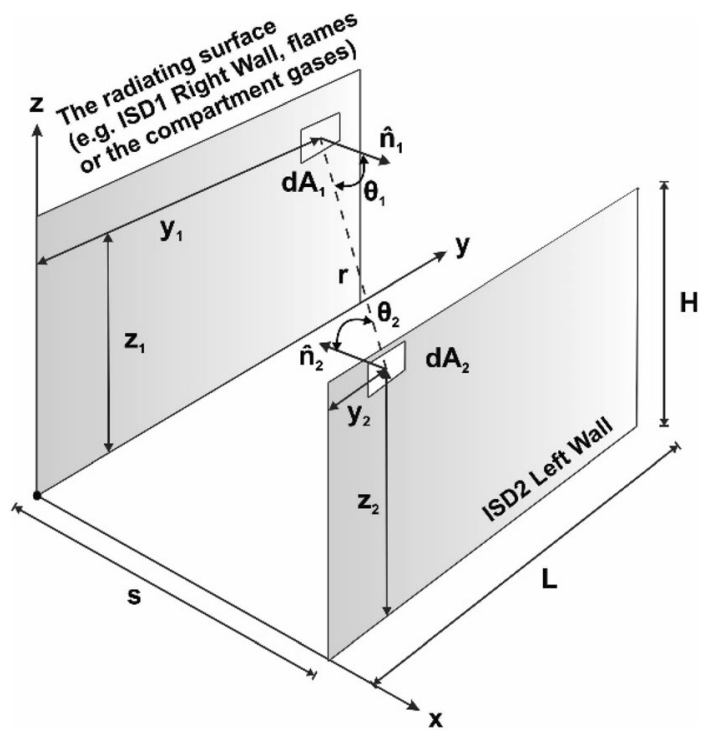

Figure 33. Derivation of the configuration factor $\varphi$ for a small element on the left wall of target dwelling exposed to a parallel radiating surface.

$$
\begin{aligned}
& r^{2}=s^{2}+\left(z_{2}-z_{1}\right)^{2}+\left(y_{2}-y_{1}\right)^{2} \\
& \cos \theta_{1}=\cos \theta_{2}=\frac{s}{r}
\end{aligned}
$$

Thus, Equation (13) can be rewritten as follows:

$$
\emptyset=\int_{0}^{H_{r}} \int_{0}^{L_{r}} \frac{\cos \theta_{1} \cos \theta_{2}}{\pi r^{2}} \cdot d y_{1} \cdot d z_{1}
$$

Note that we are only integrating over the area of the radiator under consideration (e.g., the right wall of the burning dwelling as depicted in Fig. 33 that radiates onto the left wall of the target dwelling), where $H_{r}$ is the height of the emitting surface and $L_{r}$ is the width of the emitting surface, as the point of ignition remains the infinitesimal area implying that the position of ignition is constant, thus $y_{2}$ and $\mathrm{z}_{2}$ are constant (and $\mathrm{z}_{2}=H$ ) in this work, since ignition occurred at roof level. 


\section{References}

1. UN Office for Disaster Reduction, UNISDR Terminology on Disaster Risk Reduction. The International Strategy for Disaster Reduction, pp 1-30 (2009)

2. UN-Habitat, Slum Almanac 2015/2016: Tackling Improvement in the Lives of Slum Dwellers, Nairobi (2016)

3. Cicione A, Walls RS, Kahanji C (2019) Experimental study of fire spread between multiple full scale informal settlement dwellings. Fire Saf J 105:19-27. https:/doi.org/ 10.1016/j.firesaf.2019.02.001

4. Walls RS, Eksteen R, Kahanji C, Cicione A (2019), Appraisal of fire safety interventions and strategies for informal settlements in South Africa. Disaster Prev Manag 28:343-358. https://doi.org/10.1108/DPM-10-2018-0350

5. FPASA, SA Fire Loss Statistics 2015 (2017)

6. Cicione A, Beshir M, Walls RS, Rush D (2019) Full-scale informal settlement dwelling fire experiments and development of numerical models. Fire Technol J . https://doi.org/ 10.1007/s10694-019-00894-w

7. Walls RS, Kahanji C, Cicione A, Jansen van Vuuren M (2018) Fire dynamics in informal settlement "shacks": lessons learnt and appraisal of fire behavior based on fullscale testing. In: 11th Asia-Oceania Symposium. Fire Science Technology, Taiwan (2018)

8. Cicione A, Walls RS (2019) Towards a simplified fire dynamic simulator model to analyse fire spread between multiple informal settlement dwellings based on full-scale experiments. In: 15th international conference on Exhibition. Fire Science and Engineering (2019)

9. Walls R, Zweig P (2017) Towards sustainable slums: understanding fire engineering in informal settlements. In: Bahei-El-Din Y, Hassan M (eds) Advanced Technologies for Sustainable Systems. Lecture Notes in Networks and Systems, 4th edn. Springer, Cham

10. Beshir M, Wang Y, Gibson L, Welch S, Rush D (2019) A computational study on the effect of horizontal openings on fire dynamics within informal dwellings. In: Proceedings of the ninth international seminar on fire and explosion hazards (ISFEH9), pp 512-523. https://doi.org/10.18720/spbpu/2/k19-122

11. Beshir M, Cicione A, Wang Y, Welch S, Rush D (2019) Re-visiting NIST reduced/fullscale enclosures (R/FSE) experiments (2007-2008). In: Interflam proceedings, pp 20952107

12. Lesley G, Wheeler O, Cairns R, Walls R, Rush D (2018) Fire detection in informal settlements. In: Proceedings of the remote sensing technologies and applications in urban environments, Berlin (2018)

13. Caton SE, Hakes RSP, Gorham DJ, Zhou A, Gollner MJ (2017) Review of pathways for building fire spread in the wildland urban interface part I: exposure conditions. Fire Technol 53:429-473. https://doi.org/10.1007/s10694-016-0589-z

14. Himoto K, Askimoto Y, Hokugo A, Tanaka T (2008) Risk and behavior of fire spread in a densely-built urban area. In: IAFSS, Fire Safety Science, pp 267-278. https://doi.or g/10.3801/IAFSS.FSS.9-267

15. Himoto K, Tanaka $\mathrm{T}$ (2003) A physically-based model for urban fire spread. In: IAFSS, Fire Safety Science, pp 129-140

16. de Koker N, Walls R, Cicione A, Sander Z, Loffel S, Claasen J, Fourie S, Croukamp L, Rush D (2020) Dwelling large-scale experiment of fire spread in informal settlements. Fire Technol. https://doi.org/10.1007/s10694-019-00945-2 
17. Cicione A, Walls R (2019) Estimating time to structural collapse of informal settlement dwellings based on structural fire engineering principles. In: SEMC conference. CRC Press

18. Walls R, Olivier G, Eksteen R (2017) Informal settlement fires in South Africa: fire engineering overview and full-scale tests on "shacks". Fire Saf J 91:997-1006

19. Delichatsios MA (1976) Fire growth rates in wood cribs. Combust Flame 27:267

20. Babrauskas V, Peacock RD (1992) Heat release rates: the single most important variable in fire hazard. Fire Saf J 18:255-272

21. Shields TJ, Silcock GW, Murry JJ (1994) Evaluating ignition data using the flux time product. Fire Mater 18:243-254. https://doi.org/10.1002/fam.810180407

22. Tien CL, Lee KY, Stretton AJ (2016) Radiation heat transfer. In: Hurley MJ, Gottuk DT, Hall JR, Harada K, Kuligowski ED, Puchovsky M, Watts JM, Wieczorek CJ (eds) SFPE handbook. Fire protection engineering, 4th edn. Springer, Berlin

23. Lawson DI, Simms DL (1952) The ignition of wood by radiation. Br J Appl Phys 3:288-292. https://doi.org/10.1088/0508-3443/3/9/305

24. Smith EE, Satija S (1983) Release rate model for developing fires. J Heat Transf 105:281-287. https://doi.org/10.1115/1.3245575

25. Quintiere JG, Harkleroad MT (1985) New concept for measuring flame spread properties. In: Fire safety science and engineering. ASTM STP 882, pp 239-267

26. Simms DL (1963) On the pilot ignition of wood by radiation. Combust Flame 7:253261

27. Kanury AM (1972) Ignition of cellulosic solids - a review. Fire Res Abstr Rev 14:24-52

28. Mikkola E, Wichman IS (1989) On the thermal ignition of combustible materials. Fire Mater 14:87-96. https://doi.org/10.1002/fam.810140303

29. Baker G, Spearpoint M, Fleischmann C, Wade C (2011) Selecting an ignition criterion methodology for use in a radiative fire spread submodel. Fire Mater 35:367-381. https://doi.org/10.1002/fam.1059

30. Baker G, Fleury R, Spearpoint M, Fleischmann CM, Wade C (2011) Ignition of secondary objects in a design fire simulation tool. In: Fire safety and science. https://doi.or $\mathrm{g} / 10.3801 /$ IAFSS.FSS.1

31. Karlsson B, Quintiere JG (2000) Enclosure fire dynamics. CRC Press, London. https:// doi.org/10.1016/S0379-7112(01)00031-5

32. Lee SW, Davidson RA (2010) Physics-based simulation model of post-earthquake fire spread. J Earthq Eng 14:670-687. https://doi.org/10.1080/13632460903336928

33. Wang Y, Beshir M, Cicione A, Hadden R, Krajcovic M, Rush D (2020) A full-scale experimental study on single dwelling burning behavior of informal settlement. In: IAFSS. Elsevier

34. Drysdale D (2011) An introduction to fire dynamics, 3rd edn. Wiley, New York

35. Wang Y, Bertrand C, Beshir M, Kahanji C, Walls R, Rush D (2019) Developing an experimental database of burning characteristics of combustible informal settlement dwelling materials. Fire Saf J. https://doi.org/10.1016/j.firesaf.2019.102938

36. Wang Y, Rush D (2019) Cone calorimeter tests of combustible materials found in informal settlements [dataset]. https://doi.org/10.7488/ds/2599

Publisher's Note Springer Nature remains neutral with regard to jurisdictional claims in published maps and institutional affiliations. 